\title{
A structured overview of trends and technologies used in dynamic hand orthoses
}

\author{
Ronald A. Bos ${ }^{\text {* }}$ (D), Claudia J.W. Haarman², Teun Stortelder², Kostas Nizamis², Just L. Herder ${ }^{2,3}$, \\ Arno H.A. Stienen ${ }^{2,4}$ and Dick H. Plettenburg ${ }^{1}$
}

\begin{abstract}
The development of dynamic hand orthoses is a fast-growing field of research and has resulted in many different devices. A large and diverse solution space is formed by the various mechatronic components which are used in these devices. They are the result of making complex design choices within the constraints imposed by the application, the environment and the patient's individual needs. Several review studies exist that cover the details of specific disciplines which play a part in the developmental cycle. However, a general collection of all endeavors around the world and a structured overview of the solution space which integrates these disciplines is missing. In this study, a total of 165 individual dynamic hand orthoses were collected and their mechatronic components were categorized into a framework with a signal, energy and mechanical domain. Its hierarchical structure allows it to reach out towards the different disciplines while connecting them with common properties. Additionally, available arguments behind design choices were collected and related to the trends in the solution space. As a result, a comprehensive overview of the used mechatronic components in dynamic hand orthoses is presented.
\end{abstract}

Keywords: Hand impairments, Orthosis, Exoskeleton, Rehabilitation robot, Assistive device

\section{Background}

Human hands are complex and versatile instruments. They play an essential role in the interaction between a person and the environment. Many people suffer from hand impairments like spasticity, lack of control or muscle weakness, which may be due to the consequences of stroke, paralysis, injuries or muscular diseases. Such impairments may limit an individual's independence in performing activities of daily living (ADL) and the ability to socially interact (e.g. non-verbal communication). Devices like hand exoskeletons, rehabilitation robots and assistive devices, here collectively termed as dynamic hand orthoses, aim to overcome these limitations. Their development is a fast-growing field of research and has already resulted in a large variety of devices [1-4].

Each individual has different demands for a dynamic hand orthoses. Some patients benefit from rehabilitation therapy (e.g. stroke patients [5]) while others would more

*Correspondence: r.a.bos@tudelft.nl

1 Department of Biomechanical Engineering, Delft University of Technology, 2628 CD Delft, Mekelweg 2, The Netherlands

Full list of author information is available at the end of the article likely benefit from daily assistance (e.g. Duchenne Muscular Dystrophy [6]). The resulting diversity between the different devices can be illustrated by the elaborate overviews on robotic devices [4], training modalities [3] and intention detection systems [7] they use. Clearly, there are many mechatronic components to choose from and are often the result of making particular design choices within the imposed design constraints. However, not everybody has the resources (i.e. time, accessibility) to investigate all possible design choices within these constraints. Moreover, not always are design choices reported in literature and are therefore hard to retrieve. The full potential of learning from each other's endeavors is therefore not yet fully exploited, leaving several questions in this field of research unanswered. For example, there is the discussion whether pneumatic or electric actuation is better for some applications.

The goal of this study is to collect a high quantity of dynamic hand orthoses and extract the mechatronic components which are used. Their collective properties are analyzed by using a framework which uses a generic categorization applicable for any mechatronic system: a signal domain (e.g. controllers, sensors), energy domain (e.g. 
energy sources, actuators) and mechanical domain (e.g. cables, linkages). Additionally, feasible technologies from other, but similar, disciplines are included (e.g. prosthetics, haptics). Trends are then visualized using bar charts and compared to available arguments behind design choices. This not only includes arguments from oftencited success-stories, but also from small-scale projects. Referring to the case of using pneumatic or electric actuation, this approach can answer how often each method is used and what arguments are reported, which may help in scoping further research and making a well-considered choice.

This paper is structured in different sections. The "Scope" section describes the boundaries and limitations of this study and Framework introduces the basis of the framework structure that is proposed. The "Results" section describes the quantitative results which illustrate the trends. How this relates to the functionality of the components, is discussed and summarized in the "Discussion" and "Conclusion" section, respectively.

\section{Scope}

\section{Search strategy}

The used terminology often varies between studies due to different backgrounds or field of application. For example, the term 'exoskeleton' has been presented as a type of rehabilitation robot [4] or, conversely, as a device that is not used for limb pathologies but to augment the strength of able-bodied people [8]. In this study, following the example from [9] and in conformity with ISO 8549-1:1989 [10], the term 'orthosis' is used to cover the full range of applications. The added term 'dynamic' then provides a scope towards devices that facilitate movement.

In order to collect a large quantity of dynamic hand orthoses, sources of literature were searched in Scopus, where a set of keywords was used to search in titles and abstracts. A visual representation of the search query and selection procedure can be seen in Fig. 1.

Boolean operators and wildcard symbols were used to include alternative spellings and synonyms. The used search query was (hand OR finger OR grasp*) AND ((rehab* W/10 robot* OR glove) OR (exoskelet* OR orthos?s OR "orthotic")). The inclusion criteria were defined as regular articles in the English language which presented a dynamic orthosis, supporting at least a finger joint. Using standardized terminology from ISO 85493:1989 [11], this includes the finger orthosis (FO), hand orthosis (HdO) and wrist-hand-finger orthosis (WHFO). The wrist-hand orthosis (WHO) was not included, as it stems from the deprecated term wrist orthosis (WO) [11] and therefore does not necessarily support a finger joint. Whenever a combined arm and hand support system was presented, e.g. a shoulder-elbow-wrist-hand orthosis (SEWHO), only the hand and wrist module was included. Based on the inclusion criteria, the search results underwent a title and abstract selection. Additional sources were added from relevant citations and references, as well as other possibly linked publications from the same author(s)/institution(s). Ultimately, this resulted in a total of 296 articles, describing 165 unique devices. Other supplementary sources of information used in this study include websites/brochures for commercial devices, key

a

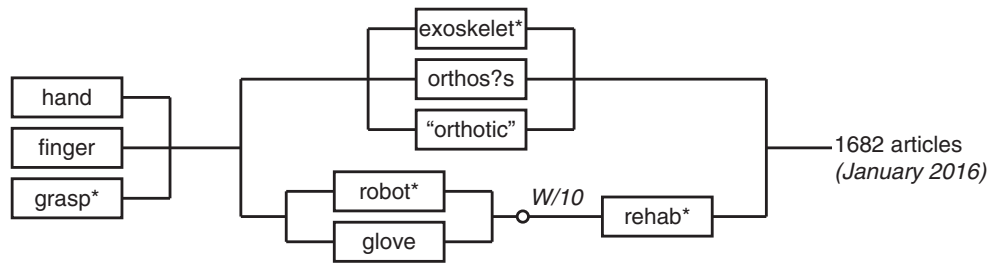

b

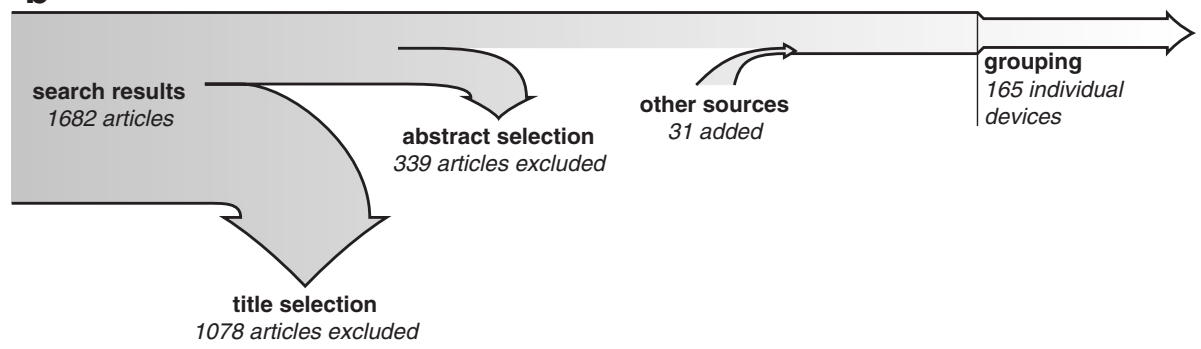

Fig. 1 Search query and selection procedure. a A visualization of the search query is shown which resulted in 1682 articles. Here, connections in series represent 'AND' and proximity ('W/10') operators, those in parallel represent 'OR' operators. b The results underwent title/abstract selection based on inclusion criteria and more sources were added through references/citations. Finally, articles were grouped in order to extract the individual devices 
review studies, standards and articles describing fundamentals on specific topics.

Year of publication was considered to cover the temporal aspect of trends and technology. Devices were placed into groups of before 2006, 2006-2010 and 2011-2015, where a device's year was defined by the most recent publication in which change to the design is reported.

\section{Applications}

As a preliminary classification, the dynamic hand orthoses were split up into different applications. These can be both medical and non-medical. Medical applications focus on enhancing or recovering hand function for a wide range of patients with disabilities in the hand. Non-medical applications, on the other hand, focus on haptic interfaces or providing additional strength for more demanding tasks. In many cases, a device's application was explicitly stated in available literature, whereas in other cases it needed to be derived from the imposed design constraints. In the latter case, the most restrictive constraints were used as distinguishing features (e.g. strict constraints on portability can indicate home use). The different applications which were used are described below.

A research tool is often used for making accurate measurements, investigating the fundamental working principle and properties of the hand [12]. Additionally, they can be used to simulate different treatments and analyze the ideal strategies for other applications [13]. Emphasis is mostly put on accuracy and reliability, rather than size and ease of use.

A clinical tool can be used for diagnostic purposes, but are mostly used for robot-assisted rehabilitation at the clinic with reduced active workload for the professional caregiver [5, 14-16].

A home rehabilitation tool can be similar to a clinical tool, but does not require personal supervision and poses more strict design constraints regarding to its size, portability and ease of use. Examples are systems that use continuous passive motion (CPM) and/or virtual reality (VR) environments, in which fun and gaming are critical aspects for increasing patient motivation [16, 17]. In most cases, progress is remotely or occasionally monitored by a clinician, allowing for personalized rehabilitation programs and the ease of staying at home. This is an increasingly popular field in rehabilitation devices, as it ideally reduces time in the clinic and maximizes hours of physical therapy [5].

A daily assistive tool is intended to assist during ADL. These types of devices are meant to be used for several hours a day without supervision from a caregiver. They are more invasive to a person's daily routine and, similar to prosthetics [18], the comfort, cosmesis and control presumably become key factors. They differ from home rehabilitation tools as they aim to assist in task execution, rather than to perform physical therapy. Sometimes physical therapy can be offered through assistance [19], in which case the daily assistance imposes the most restrictive design constraints.

A haptic device is originally a non-medical device and is used as a master hand. They interact with a VR environment or perform teleoperation while providing the user with haptic feedback. Due to similar design constraints, haptic devices become comparable with medical applications and are sometimes reported to be able to perform both (e.g. [20, 21]).

Lastly, Extra-Vehicular Activity (EVA) gloves for astronauts are included as a non-medical application. Their intended function is to compensate the high stiffness of an astronaut's gloves during activities that require a spacesuit. Similar to haptic devices, these devices are included due to comparable design constraints (e.g. [22, 23]).

\section{Framework}

\section{Structure}

In order to collectively analyze a large quantity of dynamic hand orthoses, a framework was constructed which uses the concept of tree diagrams. Firstly, the basic components of a dynamic hand orthosis were identified. Their relations are illustrated in Fig. 2, along with the interactions with the human and environment. Also shown in this figure, is a division of these components into three different domains:

- signal domain (controller, command signal, user feedback): determines the training modalities, how the human can control the device and how the human is informed about the device's status;

- energy domain (energy storage, actuation): determines the source of energy and the conversion into mechanical work that is applied through the system;

- mechanical domain (transmission, mechanism): determines how mechanical work is transported and how the different joints are supported.

These domains were chosen such that they are allinclusive and describe a generalized mechatronic system that interacts with a human. Starting from these general domains, tree diagrams were defined which describe the mechatronic components that make up the solution space. See Fig. 3 for a schematic. At each branching point, the level of detail increases. This method was chosen as it visualizes possible design choices at several levels of detail and categorizes them among three separable domains.

\section{Characteristics \& limitations}

The proposed framework was used as a subjective tool from which objective observations could be made. This is 


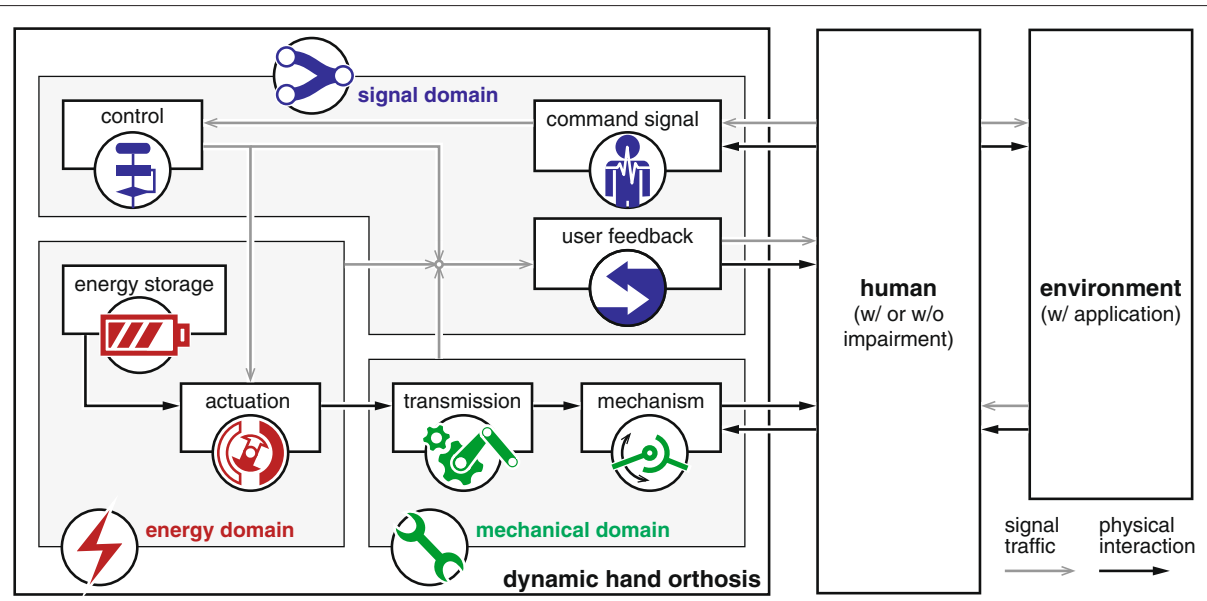

Fig. 2 Basic interactions for a dynamic hand orthosis. The device consists of several components which can be categorized into the signal, energy and mechanical domain. Gray arrows represent signal traffic, which can be made of visual or auditory stimuli, as well as electrical currents used for artificial control or the nervous system. Black arrows indicate physical interactions in the form of forces and motions. The human interacts with the device through its mechanism, but additional interactions can be provided through the command signal or user feedback

because there are multiple ways of defining the branching points, as long as the divisions are as all-inclusive as possible to accommodate all possible solutions. Moreover, it was constructed in order to discuss components and trends as a whole, rather than scoping down into full detail which is already covered in other useful reviews

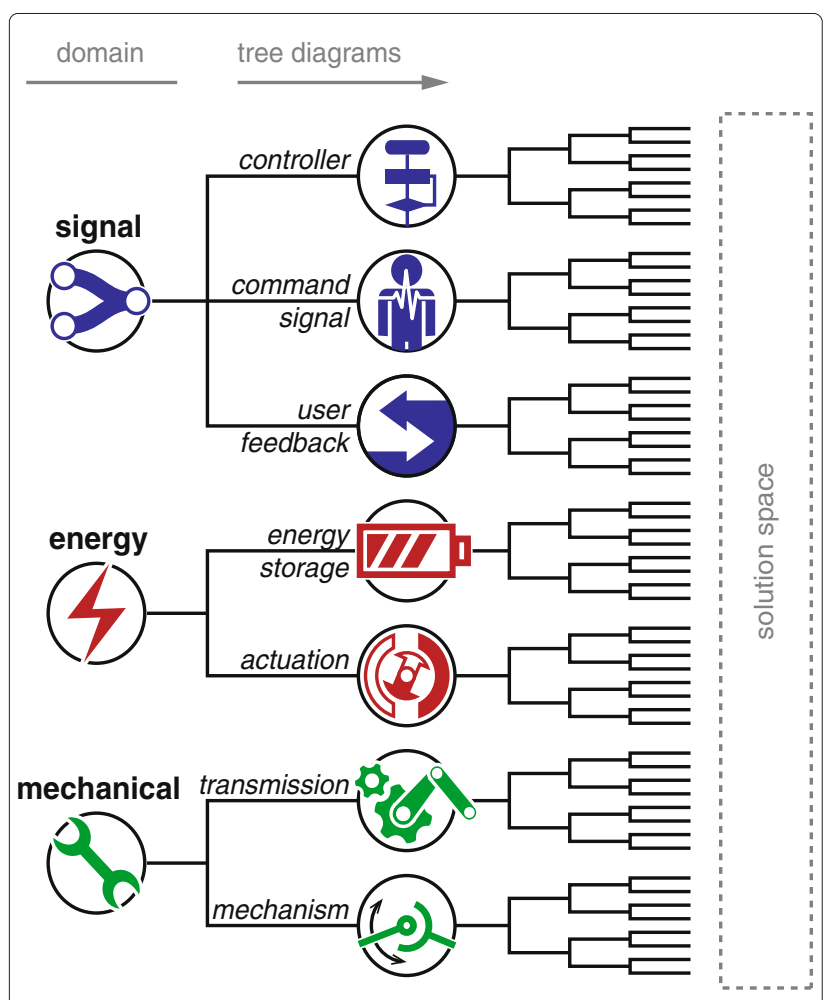

Fig. 3 Conceptual framework. Several tree diagrams are categorized into the signal, energy and mechanical domain. Towards the right side, branches lead to the solution space in increasing level of detail and classifications [3, 7, 24-26]. Existing relevant methods and terminology from these studies were used as much as possible, such that their definitions are covered in their respective sources.

The process of categorization involved investigating the available literature for each device and checking which ends of the tree branches were used. By counting all checked occurrences, the trends for each tree branch could be seen in terms of numbers grouped by year ranges. It is important to note that these numbers indicate a rate of popularity and does not always correlate to functionality, which is treated in the Discussion section. High numbers could arise because something is successful, easily accessible or common practice. Low numbers, on the other hand, could indicate that the respective solution is still experimental, not easily accessible, not well-known or it simply does not work for a given application.

A visualization of the completed framework can be seen in Figs. 4, 5 and 6 as part of the "Results" section. Embedded in this framework is a set of terms, which are discussed below per domain.

\section{Signal}

The first tree diagram within this domain encompasses the training modalities from [3] employed by the controller, subdivided according to who has authority over the device's movement [27]. The passive modality appears three times due to this additional subdivision. Automated passive training (machine authority) most resembles the traditional passive training modality. From a patient's perspective, self-triggered passive training (shared authority) can be considered to invoke different cognitive processes and-depending on the trigger-approaches the situation 
of an active-assistive modality. From the device's perspective, teleoperated passive training (human authority) implies different lower level control strategies. A second tree diagram covers the command signal required to activate the device, similar to [7]. The third tree diagram describes the modes of feedback which are available to the user, using principles from motor learning [24]. Here, standard physiological feedback is assumed and changes due the orthosis by augmentation or attenuation were considered.

\section{Energy}

Within the energy domain, the tree diagrams incorporate types of energy storage and actuation. The diagrams have a similar structure and are subdivided according to feasible types of energy and stimulus from [25] and [26]. Methods of energy storage were scoped towards portable solutions. Nuclear, wind and solar energy were considered infeasible, as well as using thermal energy for energy storage.

\section{Mechanical}

For an all-inclusive incorporation of components in the mechanical domain, one can refer to Reuleaux's classification of kinematic pairs from 1876, largely available as a digital library from the Cornell University [28]. Instead, to make the framework more compact, a more crude categorization is proposed in terms of principles encountered in dynamic hand orthoses. Hence, the first tree diagram includes transmission components which are used to transfer mechanical energy, whereas the second tree diagram describes the mechanism by its shape (i.e. structure), how the anatomical joints are supported (i.e. joint articulation) and which couplings are added to simplify the mechanism (i.e. underactuation and constraints). More specifically for joint articulation, the axis of rotation is monocentric or polycentric according to ISO 13404:2007 [29]. Jointless and external methods of articulation were added to also encompass glove and end-effector types of devices, respectively.

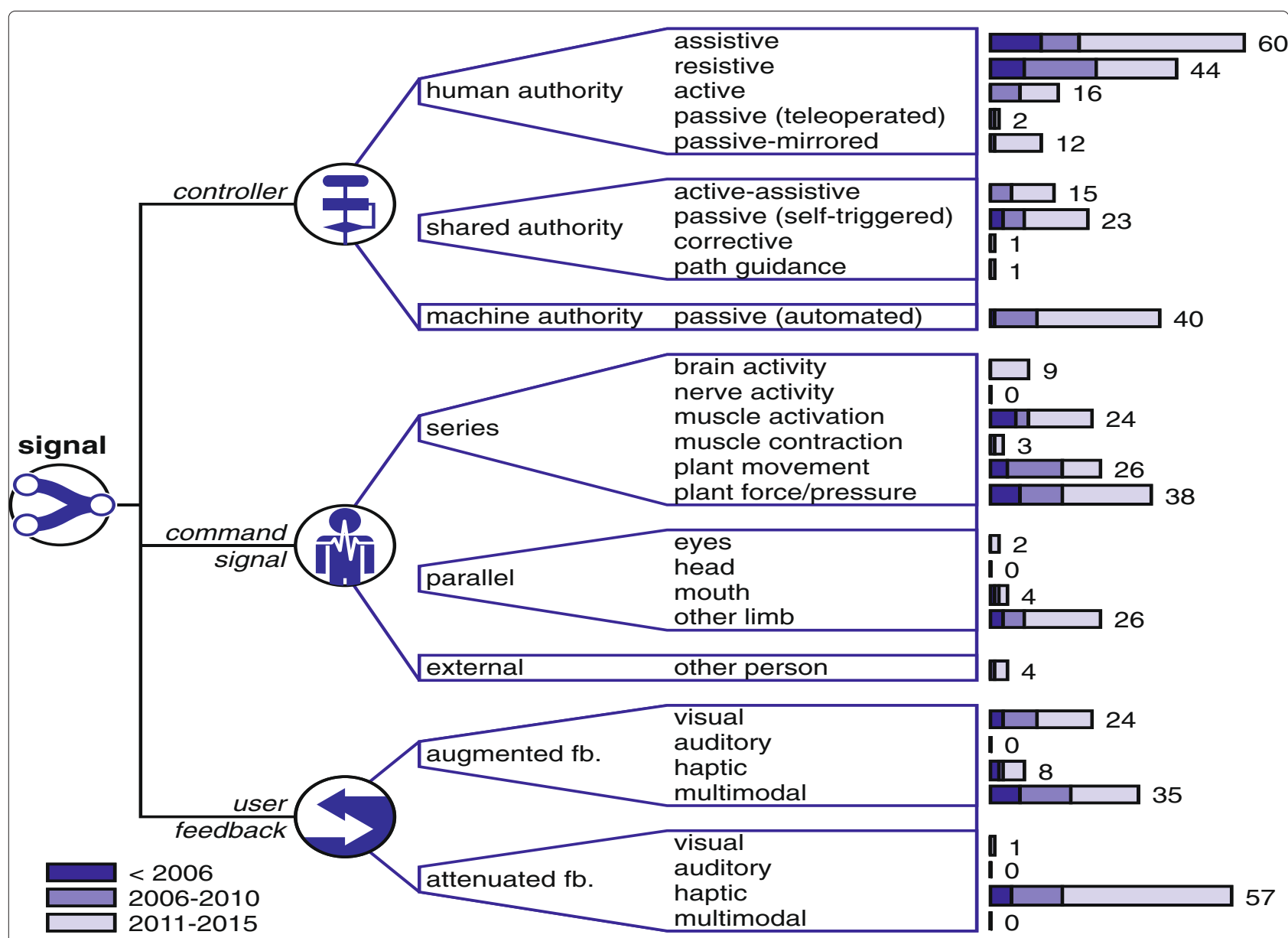

Fig. 4 Signal domain. Tree diagrams within the signal domain and their number of occurrences in found devices, grouped by year ranges 

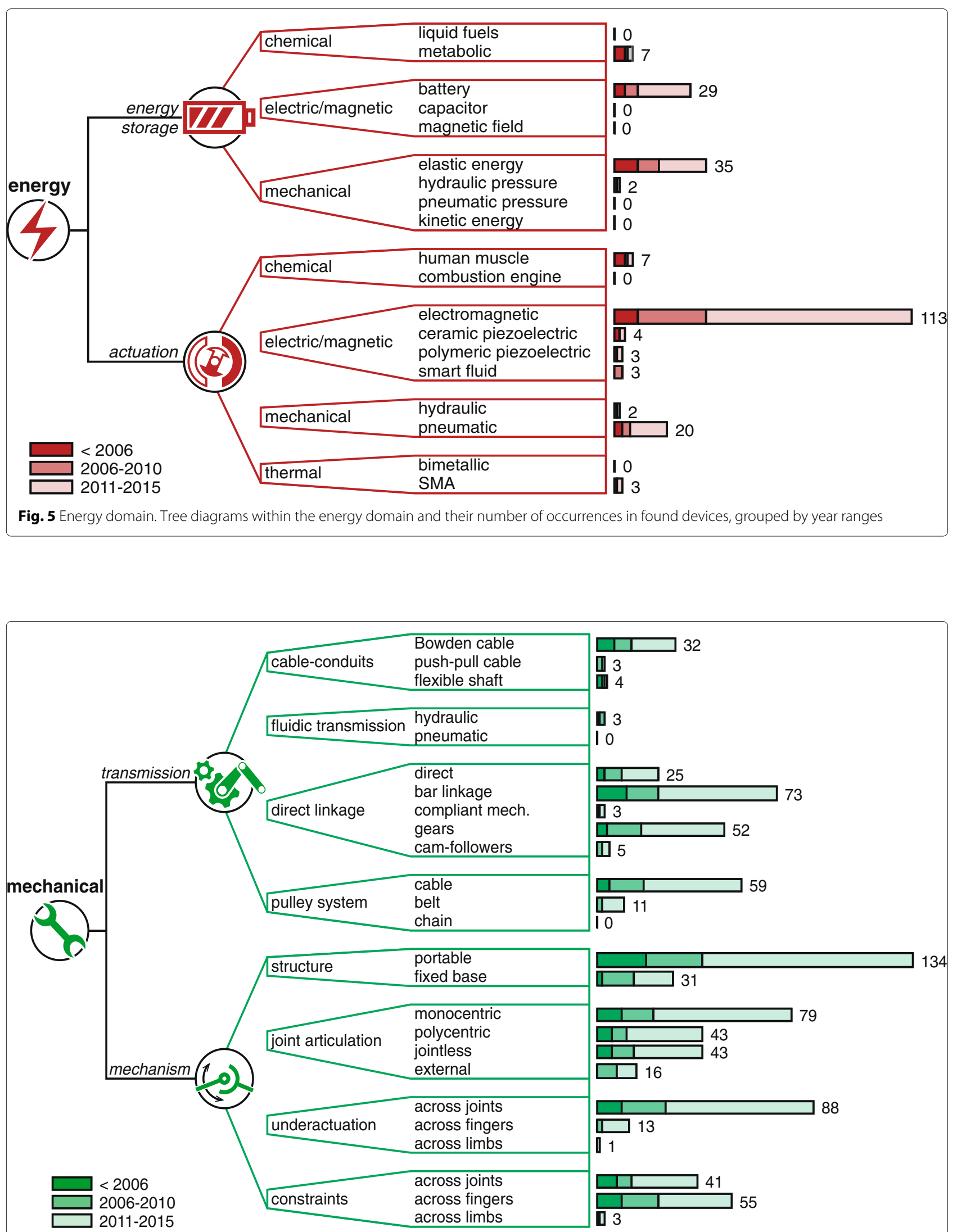

Fig. 6 Mechanical domain. Tree diagrams within the mechanical domain and their number of occurrences in found devices, grouped by year ranges 


\section{Results}

A total of 165 different dynamic hand orthoses were found, of which 109 cases presented changes most recently published between 2011 and 2015. A list of all devices is divided according to application and is shown in Tables 1, 2, 3, 4, 5 and 6 . These tables contain relevant references and additional descriptive information per device. See Additional file 1 for more detailed information on these devices and their individual categorization.

The majority of devices were home rehabilitation tools (56), followed by daily assistive tools (46), clinical tools (34) and research tools (9). Additionally, 16 haptic devices and 4 EVA glove mechanisms were found.

The resulting framework is split up into three figures, which are shown in Figs. 4, 5 and 6. The number of occurrences are added at the ends of the branches and grouped by year ranges.

\section{Discussion}

\section{General}

Results show that the development of dynamic hand orthoses has accelerated, as more than half of the found devices has undergone development in the last five years. Moreover, the amount of home rehabilitation and daily assistive tools indicate that the majority focuses on the development of devices that are used in a domestic setting, concentrating on being able to perform physical therapy at home or to help with ADL. Such observations can be linked to the trend where patient care is brought to their homes and workload on caregivers reduced [30-32].

The list of devices as presented in the tables, reveals several trends not covered in the framework. Only in rare cases, pathologies like tetraplegia, tendon injuries, arthritis or muscular weaknesses are specifically addressed in found literature. Consequently, these less targeted patient groups may fall short in specialized devices compared to more prevalent groups like stroke survivors. The tables also show that the wrist is often supported, albeit locked or assisted. In some cases, it is because the size of the mechanism or actuator module simply extends over the wrist. In other cases, however, the wrist is considered to be a crucial element in supporting overall hand function. Especially in the case of synergies or muscular weakness, supporting the combination of wrist and grasping function can be essential.

The presented framework illustrates the large span and variety of the solution space. The emerged collection of solutions can help future developers to form morphological overviews, to contemplate on the many possible combinations and to make concept choices. The unbalanced distribution and presence of outliers (i.e. very high or low number of occasions) indicate that some solutions are clearly more popular than others. A few are also never used (i.e. zero occurrences), such solutions were found by means of the framework or by inspiration from other fields of research (e.g. cineplasty from prosthetics, $[33,34])$. It should be clear, however, that these numbers do not necessarily correlate to the functionality of the component. The reasons behind these differences remain speculations, but they can be due to performance, accessibility, popularity or because a solution is still experimental. Further detailed observations on the functionalities are described below per domain.

\section{Signal}

\section{Controller}

Similar to the detailed review on training modalities [3], the passive-mirrored, corrective and path guidance modalities are used the least. They are also the least similar to the type of therapy a physical therapist can provide, and their low use implies that these methods

Table 1 Overview of included dynamic hand orthoses classified as research tool

\begin{tabular}{|c|c|c|c|c|c|c|}
\hline Name/ID & Country & Year range & ISO abbr. & Reported function & Actuator DOFb & Wrist support ${ }^{b}$ \\
\hline $\begin{array}{l}\text { MR_CHIROD } \quad \text { V.2 } \\
{[113-115]}\end{array}$ & USA & $2005-2008$ & $\mathrm{HdO}$ & post-stroke measurement & 1 & $N / A$ \\
\hline FingerBot [48] & USA & 2010 & $\mathrm{FO}$ & post-stroke measurement & 3 & N/A \\
\hline ATX [116] & USA & 2011 & $\mathrm{FO}$ & post-stroke measurement & 5 & N/A \\
\hline Fiorilla $[12,117]$ & Italy & 2009-2011 & $\mathrm{FO}$ & normal measurement & 2 & $\begin{array}{l}\text { Limited (PS) } \\
\text { Locked (FE, RUD) }\end{array}$ \\
\hline Ramos $[118,119]$ & Germany & 2009-2012 & WHFO & post-stroke therapy & 4 & Locked (PS, FE, RUD) \\
\hline Tang [120-123] & Japan & $2011-2013$ & $\mathrm{FO}$ & post-stroke measurement/therapy & 1 & Limited (FE) \\
\hline CAFE $[13,124,125]$ & USA & 2007-2014 & $\mathrm{FO}$ & post-stroke measurement & 6 & Locked (FE, RUD) \\
\hline Kim 2 [126] & South Korea & 2015 & WHFO & general measurement/therapy & 1 & Limited (PS, FE, RUD) \\
\hline Lee 2 [127] & South Korea & 2015 & $\mathrm{HdO}$ & post-stroke measurement & 5 & $\mathrm{~N} / \mathrm{A}$ \\
\hline
\end{tabular}

a Year ranges are determined by the year span between found literature sources and my differ from the actual time of development

${ }^{b}$ Actuator DOF = number of individually controlled actuators (zero means fully passive)

'Wrist can be assisted, resisted, limited or locked [29] in pronation/supination (PS), flexion/extension (FE) and radial/ulnar deviation (RUD) 
Table 2 Overview of included dynamic hand orthoses classified as clinical tool

\begin{tabular}{|c|c|c|c|c|c|c|}
\hline Name/ID & Country & Year range $\mathrm{e}^{\mathrm{a}}$ & ISO abbr. & Reported function & Actuator DOF & Wrist support ${ }^{b}$ \\
\hline HWARD [30] & USA & 2005 & WHFO & post-stroke therapy & 2 (+1 wrist) & $\begin{array}{l}\text { Locked (PS, RUD) } \\
\text { Assisted (FE) }\end{array}$ \\
\hline HIFE [20] & Slovenia & 2006 & $\mathrm{FO}$ & general physical therapy & 2 & Locked (PS, FE, RUD) \\
\hline Gentle/G hand device [49] & UK & 2007 & WHFO & post-stroke therapy & 3 & Locked (FE, RUD) \\
\hline $\begin{array}{l}\text { InMotion Hand Robot } \\
{[89,128,129]}\end{array}$ & USA & $1991-2007$ & $\mathrm{HdO}$ & post-stroke therapy & 1 & N/A \\
\hline CPM/CAM [130] & Canada & 2008 & $\mathrm{HdO}$ & general CPM/CAM & 2 & N/A \\
\hline Fu $[90,131]$ & China & 2008 & $\mathrm{FO}$ & general CPM & 2 & N/A \\
\hline $\begin{array}{l}\text { ADLER FES grasp glove } \\
{[132,133]}\end{array}$ & USA & $2007-2009$ & $\mathrm{HdO}$ & post-stroke therapy & Not clear & Not clear \\
\hline $\begin{array}{l}\text { IntelliArm hand module } \\
{[134,135]}\end{array}$ & USA & $2008-2009$ & WHFO & post-stroke measurement/therapy & 1 (+2 wrist) & $\begin{array}{l}\text { Assisted (PS, FE) } \\
\text { Locked (RUD) }\end{array}$ \\
\hline Sun $[72,136]$ & China & $2006-2009$ & WHFO & post-stroke therapy & 2 & Limited (PS, FE, RUD) \\
\hline Wang [137-141] & China & 2009-2011 & $\mathrm{FO}$ & general physical therapy & 4 & Limited (FE, RUD) \\
\hline Yamaura [142] & Japan & 2009 & $\mathrm{FO}$ & general physical therapy & 2 & N/A \\
\hline $\begin{array}{l}\text { HenRiE grasp module } \\
\text { [143-145] }\end{array}$ & Slovenia & $2008-2010$ & WHFO & post-stroke therapy & 0 & Locked (FE, RUD) \\
\hline HEXORR [64] & USA & 2010 & WHFO & post-stroke therapy & 2 & Locked (PS, FE, RUD) \\
\hline PneuGlove [146-148] & USA & 2006-2010 & $\mathrm{HdO}$ & post-stroke therapy & 5 & N/A \\
\hline Unluhisarcikli [149] & USA & 2008-2010 & WHFO & post-stroke therapy & 2 (+1 wrist) & Assisted (PS) \\
\hline ExoHand [21] & Germany & 2012 & WHFO & tele-operation, post-stroke therapy & 8 & Limited (FE, RUD) \\
\hline iHandRehab $[91,137,150]$ & China & 2009-2012 & $\mathrm{HdO}$ & general physical therapy & 8 & N/A \\
\hline Kim 1 [151] & South Korea & 2013 & WHFO & post-stroke therapy & 10 & $\begin{array}{l}\text { Locked (PS) } \\
\text { Limited (FE, RUD) }\end{array}$ \\
\hline Sooraj [152] & India & 2013 & WHFO & general physical therapy & 5 & Locked (PS, FE, RUD) \\
\hline Amadeo [153-155] & Austria & 2010-2014 & WHFO & general measurement/therapy & 5 & Locked (PS, FE, RUD) \\
\hline $\begin{array}{l}\text { AMES hand module } \\
{[53,54,156,157]}\end{array}$ & USA & 2009-2014 & WHFO & post-stroke therapy & 1 (+1 wrist) & $\begin{array}{l}\text { Locked (PS, RUD) } \\
\text { Assisted (FE) }\end{array}$ \\
\hline AssistOn-Finger [109, 158] & Turkey & 2009-2014 & $\mathrm{FO}$ & tendon injury treatment & 1 & Locked (FE, RUD) \\
\hline Bi [159-161] & China & $2011-2014$ & WHFO & post-stroke therapy & 5 & Locked (FE, RUD) \\
\hline Chan [162] & Malaysia & 2014 & $\mathrm{HdO}$ & $\begin{array}{l}\text { post-stroke therapy, general assis- } \\
\text { tance }\end{array}$ & 3 & N/A \\
\hline FINGER $[52,163,164]$ & USA & $2011-2014$ & $\mathrm{FO}$ & post-stroke therapy & 1 & Locked (PS, FE, RUD) \\
\hline HIT-Glove [165-168] & China & 2010-2014 & $\mathrm{FO}$ & post-stroke therapy & 6 & N/A \\
\hline Kawasaki [44, 169-172] & Japan & 2004-2014 & WHFO & post-stroke therapy & 16 (+ 2 wrist) & $\begin{array}{l}\text { Assisted (PS, FE) } \\
\text { Locked (RUD) }\end{array}$ \\
\hline King $[47,173,174]$ & USA & 2009-2014 & $\mathrm{HdO}$ & post-stroke therapy & 7 & N/A \\
\hline PMHand [175] & UK & 2014 & $\mathrm{HdO}$ & post-stroke therapy & 1 & N/A \\
\hline ReachMAN2 $[106,176,177]$ & UK & 2009-2014 & WHFO & post-stroke therapy & 1 (+1 wrist) & $\begin{array}{l}\text { Assisted (PS) } \\
\text { Locked (FE, RUD) }\end{array}$ \\
\hline Reha-Digit [178-180] & Germany & $2008-2014$ & $\mathrm{HdO}$ & general CPM & 1 & Limited (PS, FE, RUD) \\
\hline Ushiba [181] & Japan & 2014 & WHFO & post-stroke therapy & 1 & Locked (FE, RUD) \\
\hline IHRG [182-187] & Romania & $2013-2015$ & $\mathrm{HdO}$ & post-stroke therapy & 4 & N/A \\
\hline READAPT [188-192] & USA & 2008-2015 & WHFO & post-stroke measurement/therapy & 8 (+3 wrist) & Assisted (PS, FE, RUD) \\
\hline
\end{tabular}

a Year ranges are determined by the year span between found literature sources and my differ from the actual time of development

${ }^{b}$ 2Actuator DOF = number of individually controlled actuators (zero means fully passive)

${ }^{c}$ Wrist can be assisted, resisted, limited or locked [29] in pronation/supination (PS), flexion/extension (FE) and radial/ulnar deviation (RUD) 
Table 3 Overview of included dynamic hand orthoses classified as home rehabilitation tool

\begin{tabular}{|c|c|c|c|c|c|c|}
\hline Name/ID & Country & Year range $^{a}$ & ISO abbr. & Reported function & Actuator DOF ${ }^{b}$ & Wrist support ${ }^{b}$ \\
\hline Sarakoglou [50] & UK & 2004 & $\mathrm{HdO}$ & general physical therapy & 7 & N/A \\
\hline Luo $[193,194]$ & USA & 2005 & $\mathrm{HdO}$ & post-stroke therapy & 1 & N/A \\
\hline Mulas [195] & Italy & 2005 & WHFO & general physical therapy & 2 & Limited (PS, FE, RUD) \\
\hline Haptic Knob [31, 196] & Singapore & 2007 & WHFO & post-stroke therapy & 1 (+1 wrist) & $\begin{array}{l}\text { Assisted (PS) } \\
\text { Limited (FE, RUD) }\end{array}$ \\
\hline MRAGES [197] & USA & 2007 & $\mathrm{HdO}$ & general physical therapy & 5 & N/A \\
\hline Wege $[37,87,198-200]$ & Germany & $2005-2007$ & $\mathrm{HdO}$ & general physical therapy & 20 & N/A \\
\hline Carpi [201] & Italy & 2008 & WHFO & $\begin{array}{l}\text { general impairment } \\
\text { compensation }\end{array}$ & 1 & Locked (FE, RUD) \\
\hline HandCARE [202] & Singapore & 2008 & $\mathrm{HdO}$ & post-stroke therapy & 1 & Limited (PS, FE, RUD) \\
\hline Chen [203] & China & 2009 & WHFO & post-stroke therapy & 5 & Locked (FE, FE, RUD) \\
\hline HIRO III [204] & Japan & 2010 & $\mathrm{HdO}$ & general physical therapy & 15 & N/A \\
\hline Mohamaddan [205] & Malaysia & 2010 & $\mathrm{HdO}$ & post-stroke therapy & 2 & N/A \\
\hline $\begin{array}{l}\text { NeReBot hand add-on } \\
{[60,206]}\end{array}$ & Italy & 2009-2010 & WHFO & post-stroke therapy & 1 & Locked (PS, FE, RUD) \\
\hline Burton $[207,208]$ & UK & 2011-2012 & WHFO & post-stroke therapy & 6 & Limited (FE, RUD) \\
\hline J-Glove $[40,209]$ & USA & 2009-2011 & WHFO & post-stroke therapy & 1 & Locked (FE, RUD) \\
\hline PRoGS [210] & Singapore & 2010-2011 & WHFO & post-stroke therapy & 5 & N/A \\
\hline SaeboFlex $[211,212]$ & USA & 2011 & WHFO & $\begin{array}{l}\text { post-stroke therapy, hypertonia } \\
\text { compensation }\end{array}$ & 0 & Locked (FE, RUD) \\
\hline Tzemanaki [213] & UK & 2011 & $\mathrm{HdO}$ & general therapy & 5 & N/A \\
\hline DULEX-II $[45,214]$ & South Korea & 2009-2012 & WHFO & post-stroke therapy & 2 (+ 1 wrist) & $\begin{array}{l}\text { Assisted (FE) } \\
\text { Locked (RUD) }\end{array}$ \\
\hline ExoFlex [215] & USA & 2012 & $\mathrm{HdO}$ & general therapy & 4 & N/A \\
\hline HANDEXOS $[98,216,217]$ & Italy & 2009-2012 & $\mathrm{FO}$ & post-stroke therapy & 1 & N/A \\
\hline JACE H440 Hand CPM [218] & USA & 2012 & WHFO & general physical therapy & 1 & Locked (PS, FE, RUD) \\
\hline Kazemi [219] & Canada & 2012 & WHFO & post-stroke measurement/therapy & 1 (+1 wrist) & Assisted (PS) \\
\hline Naidu [220, 221] & South Africa & $2011-2012$ & WHFO & post-stroke therapy & 2 (+1 wrist) & $\begin{array}{l}\text { Assisted (PS) } \\
\text { Locked (FE, RUD) }\end{array}$ \\
\hline Polotto [222] & Canada & 2012 & $\mathrm{FO}$ & post-stroke therapy/assistance & 4 & N/A \\
\hline $\begin{array}{l}\text { WaveFlex Hand CPM } \\
\text { [223-225] }\end{array}$ & USA & 1997-2012 & WHFO & general physical therapy & 1 & Locked (FE, RUD) \\
\hline Wu $[71,75,226-229]$ & China & 2008-2012 & WHFO & post-stroke therapy & 2 & $\begin{array}{l}\text { Limited (PS) } \\
\text { Locked (FE, RUD) }\end{array}$ \\
\hline CAFEx [230] & Malaysia & 2013 & $\mathrm{HdO}$ & post-stroke therapy & 1 & N/A \\
\hline Gloreha Lite $[231,232]$ & Italy & 2013 & $\mathrm{HdO}$ & general physical therapy & 5 & N/A \\
\hline Hand of Hope [105, 233-236] & China & 2010-2013 & $\mathrm{HdO}$ & post-stroke therapy & 5 & N/A \\
\hline mRes [95] & Germany & 2013 & $\mathrm{HdO}$ & post-stroke therapy & 4 & N/A \\
\hline Orlando $[237,238]$ & India & 2010-2013 & $\mathrm{FO}$ & post-stroke therpapy & 3 & N/A \\
\hline Rahman $[239,240]$ & Australia & 2012-2013 & WHFO & post-stroke therapy & 5 & N/A \\
\hline Shafi [241] & Pakistan & 2013 & $\mathrm{HdO}$ & general physical therapy & 4 & N/A \\
\hline Song [242] & Taiwan & 2013 & $\mathrm{HdO}$ & post-stroke therapy/assistance & 3 & Limited (FE) \\
\hline $\begin{array}{l}\text { UoA hand exoskeleton } \\
{[61,74]}\end{array}$ & Australia & 2012-2013 & WHFO & post-stroke therapy & 11 & Limited (PS, FE, RUD) \\
\hline BiomHED $[97,243,244]$ & USA & 2014 & WHFO & post-stroke therapy & 7 & $\begin{array}{l}\text { Limited (PS) } \\
\text { Locked (FE, RUD) }\end{array}$ \\
\hline Coffey [245] & Ireland & 2014 & WHFO & post-stroke therapy & 1 & $\begin{array}{l}\text { Limited (PS, RUD) } \\
\text { Assisted (FE) }\end{array}$ \\
\hline Guo [246] & China & 2014 & $\mathrm{FO}$ & post-stroke therapy & 1 & N/A \\
\hline
\end{tabular}


Table 3 Overview of included dynamic hand orthoses classified as home rehabilitation tool (Continued)

\begin{tabular}{|c|c|c|c|c|c|c|}
\hline HEXOSYS-I [86, 247, 248] & Italy & 2010-2014 & $\mathrm{HdO}$ & general physical therapy & 2 & N/A \\
\hline IOTA [249] & USA & 2014 & WHFO & pediatric rehabilitation & 2 & N/A \\
\hline Maestra $[250,251]$ & France & 2014 & WHFO & general physical therapy & 1 & Assisted (PS, FE, RUD) \\
\hline Maestra Portable $[250,251]$ & France & 2014 & WHFO & general physical therapy & 1 & Locked (FE, RUD) \\
\hline PAFEx $[38,252]$ & Japan & 2009-2014 & $\mathrm{HdO}$ & post-stroke therapy & 3 & N/A \\
\hline Pu $[253,254]$ & Taiwan & 2014-2015 & WHFO & general physical therapy & 4 & Locked (FE, RUD) \\
\hline ReHand-II $[255,256]$ & China & 2014 & $\mathrm{HdO}$ & post-stroke therapy & 2 & N/A \\
\hline ReHapticKnob [257-259] & Switzerland & $2011-2014$ & WHFO & post-stroke measurement/therapy & 1 (+1 wrist) & Assisted (PS) \\
\hline $\mathrm{SPO}[32,260,261]$ & Netherlands & 2013-2014 & WHFO & post-stroke therapy & 0 & $\begin{array}{l}\text { Resisted (F), Assisted (E) } \\
\text { Locked (RUD) }\end{array}$ \\
\hline Tang $2[81,262]$ & China & 2013-2014 & $\mathrm{HdO}$ & general physical therapy & 10 & N/A \\
\hline $\begin{array}{l}\text { ULERD hand module } \\
{[263,264]}\end{array}$ & China & 2013-2014 & WHFO & post-stroke therapy & 1 (+2 wrist) & $\begin{array}{l}\text { Assisted (PS, FE) } \\
\text { Locked (RUD) }\end{array}$ \\
\hline Ab Patar $[265,266]$ & Japan & 2015 & $\mathrm{HdO}$ & post-stroke therapy & 3 & N/A \\
\hline HEXOSYS-II [267-270] & Italy & 2010-2015 & WHFO & general physical therapy & 5 & Limited (FE, RUD) \\
\hline $\mathrm{HX}[96,271-274]$ & Italy & 2013-2015 & WHFO & general physical therapy & 2 & Locked (RUD) \\
\hline NESS H2O0 [275, 276] & USA & 1996-2015 & WHFO & general physical therapy & Not clear & Not clear \\
\hline Ramirez [277] & Mexico & 2015 & WHFO & general physical therapy & 6 & $\begin{array}{l}\text { Limited (PS) } \\
\text { Locked (FE, RUD) }\end{array}$ \\
\hline Richards [278] & UK & 2015 & $\mathrm{HdO}$ & post-stroke rehabilitation & 2 (+1 palm) & N/A \\
\hline SAO-i3 $[279,280]$ & Netherlands & 2014-2015 & WHFO & post-stroke therapy & 1 & Assisted (FE, RUD) \\
\hline
\end{tabular}

a Year ranges are determined by the year span between found literature sources and my differ from the actual time of development

${ }^{\mathrm{b}}$ Actuator DOF = number of individually controlled actuators (zero means fully passive)

'Wrist can be assisted, resisted, limited or locked [29] in pronation/supination (PS), flexion/extension (FE) and radial/ulnar deviation (RUD)

are still in experimental phase. Little can be said about their efficacy, as the exact working principles behind a successful rehabilitation program are not yet fully known [17]. Nonetheless, their development helps in understanding these principles and exploring the full potential of involving robotic technology.

In general, the training modalities which are mostly used in dynamic hand orthoses, have the human in full authority over the movement. Due to the large amount of daily assistive tools, home rehabilitation tools and the inclusion of haptic devices, the assistive, resistive and passive training modalities show the highest frequencies and skew the distribution compared to a previous review on training modalities [3]. Especially for daily assistive tools, emphasis is more often put on regaining hand function rather than recovery of the physiological abilities. In these cases, assistive and self-triggered passive modalities are more popular.

\section{Command signal}

Detecting the user's intention to serve as a command signal for the device is one of the larger challenges, because the control of the device is expected to be both intuitive and robust [35]. From the inspected dynamic hand orthoses, most state that measuring the command signal in series with the intended movement is most intuitive $[23,36]$. This is also reflected in the results, as 100 cases use methods in series against 32 cases in parallel. The use of interaction forces and motions from the human plant is the most popular method of using a command signal in series. Here, issues due to sweat, sensor placement and signal quality are less interfering as compared to alternatives. Electromyography (EMG) as a measure of muscle activation is also often used and widely accepted in externally powered upper limb prosthetics, but more challenges are encountered in electrode placement and separation of signals [37-41]. Nonetheless, recent studies have shown that both methods (plant forces/motions and EMG) are feasible as a control interface [42, 43].

Parallel methods are considered less complex, useful for self-controlled mirror therapy [44, 45], or sometimes inevitable due to the absence of physiological signals directly relating to the intended motion $[36,46]$. However, these methods can also take away useful functionalities (e.g. bimanual tasks, muscle use) and providing intuitive control is important to achieve user acceptance, stressing the advantages of using command signals in series whenever this fits within the design constraints. 
Table 4 Overview of included dynamic hand orthoses classified as daily assistive tool

\begin{tabular}{|c|c|c|c|c|c|c|}
\hline Name/ID & Country & Year range $^{a}$ & ISO abbr. & Reported function & Actuator DOF ${ }^{\mathrm{b}}$ & Wrist support $^{\mathrm{b}}$ \\
\hline $\begin{array}{l}\text { Hardiman project } \\
\text { [281-283] }\end{array}$ & USA & 1967-1971 & WHFO & power assistance & 2 (+2 wrist) & $\begin{array}{l}\text { Assisted (PS, FE) } \\
\text { Locked (RUD) }\end{array}$ \\
\hline Hamonet [284] & France & 1974 & $\mathrm{HdO}$ & tetraplegic assistance & 1 & N/A \\
\hline $\begin{array}{l}\text { K U finger splint S-type } \\
\text { [285] }\end{array}$ & Japan & 1978 & WHFO & $\begin{array}{l}\text { general impairment compen- } \\
\text { sation }\end{array}$ & 0 & Limited (FE, RUD) \\
\hline $\begin{array}{l}\text { K U finger splint W-type } \\
\text { [285] }\end{array}$ & Japan & 1978 & WHFO & $\begin{array}{l}\text { general impairment compen- } \\
\text { sation }\end{array}$ & 0 & Limited (FE, RUD) \\
\hline WDFHO $[102,286,287]$ & USA & 1978-2013 & WHFO & tetraplegic assistance & 1 & Assisted (FE), Locked (RUD) \\
\hline Dollfus [288] & France & 1984 & $\mathrm{HdO}$ & tetraplegic assistance & 1 & N/A \\
\hline Benjuya [51] & USA & 1990 & $\mathrm{HdO}$ & tetraplegic assistance & 1 & N/A \\
\hline Slack [289] & Canada & 1992 & WHFO & tetraplegic assistance & 1 & Limited (PS, FE, RUD) \\
\hline Brown [290] & USA & 1993 & $\mathrm{HdO}$ & tetraplegic assistance & 5 & N/A \\
\hline SMART WHO [80] & Canada & 1993 & WHFO & tetraplegic assistance & 1 & Limited (FE), Locked (RUD) \\
\hline DiCicco [291] & USA & 2004 & WHFO & tetraplegic assistance & 2 & Limited (FE, RUD) \\
\hline Watanabe [55, 292] & Japan & 2005-2007 & WHFO & arthritis assistance & 1 & Locked (FE, RUD) \\
\hline Alutei [293] & Romania & 2009 & WHFO & general assistance & 1 (+1 wrist) & $\begin{array}{l}\text { Assisted (PS) } \\
\text { Locked (FE, RUD) }\end{array}$ \\
\hline Moromugi 1 [173] & Japan & 2009 & $\mathrm{HdO}$ & general assistance & 7 & N/A \\
\hline Exo-Finger [46] & Japan & 2010 & $\mathrm{HdO}$ & post-stroke assistance & 1 & N/A \\
\hline Moromugi 2 [294] & Japan & 2010 & $\mathrm{HdO}$ & tetraplegic assistance & 1 & Locked (RUD) \\
\hline Tadano [73] & Japan & 2010 & $\mathrm{HdO}$ & power assistance & 10 & $\mathrm{~N} / \mathrm{A}$ \\
\hline HandSOME [62] & USA & 2011 & WHFO & $\begin{array}{l}\text { post-stroke impairment com- } \\
\text { pensation }\end{array}$ & 0 & Locked (FE, RUD) \\
\hline PowerGrip [295] & USA & 2011 & WHFO & general assistance & 1 & Locked (FE, RUD) \\
\hline Toya [296] & Japan & 2011 & $\mathrm{HdO}$ & general assistance & 4 & $\mathrm{~N} / \mathrm{A}$ \\
\hline Baqapuri [297] & Pakistan & 2012 & WHFO & tetraplegic assistance & 4 & Limited (PS, FE, RUD) \\
\hline SEM Glove [94] & Sweden & 2012 & $\mathrm{HdO}$ & general assistance & 3 & N/A \\
\hline Arata [63] & Japan & 2013 & $\mathrm{HdO}$ & general therapy/assistance & 1 & Limited (FE, RUD) \\
\hline $\begin{array}{l}\text { KULEX grasping module } \\
\text { [298-300] }\end{array}$ & South Korea & 2012-2013 & WHFO & general assistance & 1 (+3 wrist) & Assisted (PS, FE, RUD) \\
\hline Lambercy [301] & Switzerland & 2013 & $\mathrm{FO}$ & post-stroke therapy/assistance & 1 & N/A \\
\hline Moromugi 3 [302] & Japan & 2013 & $\mathrm{HdO}$ & tetraplegic assistance & 3 & $\mathrm{~N} / \mathrm{A}$ \\
\hline $\begin{array}{l}\text { MUNDUS hand orthosis } \\
\text { [36] }\end{array}$ & Italy & 2013 & $\mathrm{HdO}$ & tetraplegic assistance & 1 & N/A \\
\hline Zheng [82] & China & 2013 & $\mathrm{HdO}$ & general assistance & Not clear & Not clear \\
\hline Aw [83] & Australia & 2014 & $\mathrm{HdO}$ & general assistance & 14 & N/A \\
\hline Kudo [303] & Japan & 2014 & $\mathrm{HdO}$ & tetraplegic assistance & 1 & N/A \\
\hline Lee $1[84,304]$ & South Korea & $2012-2014$ & $\mathrm{HdO}$ & general assistance & 5 & N/A \\
\hline Nishad [305] & India & 2014 & $\mathrm{HdO}$ & general therapy/assistance & 8 & Limited (FE, RUD) \\
\hline OFX $[58,306,307]$ & South Korea & 2013-2014 & WHFO & general assistance & 1 & Locked (FE, RUD) \\
\hline Puzo [308] & USA & 2014 & $\mathrm{HdO}$ & general therapy/assistance & 5 & N/A \\
\hline SaeboGlove [212] & USA & 2014 & WHFO & $\begin{array}{l}\text { general impairment compen- } \\
\text { sation }\end{array}$ & 0 & Locked (FE, RUD) \\
\hline Sasaki $[39,41,309]$ & Japan & 2004-2014 & $\mathrm{HdO}$ & general assistance & 5 & N/A \\
\hline $\begin{array}{l}\text { BRAVO Hand Exoskele- } \\
\text { ton [310-312] }\end{array}$ & Italy & $2011-2015$ & $\mathrm{HdO}$ & post-stroke therapy/assistance & 2 & N/A \\
\hline Conti [313] & Italy & 2015 & $\mathrm{HdO}$ & general assistance & 4 & N/A \\
\hline Cui [314] & Australia & 2015 & $\mathrm{HdO}$ & general assistance & 5 & N/A \\
\hline
\end{tabular}


Table 4 Overview of included dynamic hand orthoses classified as daily assistive tool (Continuation)

\begin{tabular}{|c|c|c|c|c|c|c|}
\hline Delph II [99, 315] & USA & 2013-2015 & $\mathrm{HdO}$ & post-stroke therapy/assistance & 5 & N/A \\
\hline ExoGlove [316-319] & Singapore & 2015 & $\mathrm{HdO}$ & general therapy/assistance & 1 & N/A \\
\hline Gasser [320] & USA & 2015 & $\mathrm{HdO}$ & post-stroke assistance & 2 & N/A \\
\hline $\begin{array}{l}\text { Hasegawa } \\
\text { [321-326] }\end{array}$ & Japan & 2008-2015 & WHFO & power assistance & 8 (+ 4 wrist) & Assisted (PS, FE) \\
\hline OHAE $[92,327-330]$ & USA & 2009-2015 & WHFO & general assistance & 3 & Limited (FE, RUD) \\
\hline $\begin{array}{l}\text { Polygerinos [19, 331, } \\
332]\end{array}$ & USA & 2013-2015 & $\mathrm{HdO}$ & general therapy/assistance & 4 & N/A \\
\hline $\begin{array}{l}\text { SNU Exo-Glove } \\
{[85,93,333-335]}\end{array}$ & South Korea & $2011-2015$ & WHFO & general therapy/assistance & 3 & N/A \\
\hline
\end{tabular}

ayear ranges are determined by the year span between found literature sources and my differ from the actual time of development

${ }^{\mathrm{b}}$ Actuator DOF = number of individually controlled actuators (zero means fully passive)

cWrist can be assisted, resisted, limited or locked [29] in pronation/supination (PS), flexion/extension (FE) and radial/ulnar deviation (RUD)

Other methods that were encountered appear less feasible, less successful or experimental. For example, peripheral nerve interfaces (PNI) are not encountered as they can be considered as too invasive; measuring brain activity through electroencephalography (EEG) has an increased risk of false positives and negatives (even with a binary system [47]); force myography (FMG) remains in experimental phase [7]; and, mechanomyography (MMG) is subject to environmental sounds and limb-movement artifacts [7].

\section{User feedback}

A large portion of the investigated devices (67 out of 165) use augmented user feedback. Especially multimodal feedback is a popular method of providing the user with additional cues. Here, VR environments are often used as a platform to provide audiovisual cues (e.g. [48]), audiovisuohaptic cues (e.g. [49]) or haptic rendering (e.g. [50]). Amongst others, this can enhance a sense of reality or provide information on performance. Augmenting unimodal feedback (i.e. visual, auditory or haptic) can also be used in various manners. For example, the force exerted by the device can be visualized [51], music can facilitate motor output [52] and stimulation of the muscle spindles through vibrations can give an enhanced sensation of motion to further enhance rehabilitation success $[53,54]$.
From a different perspective, augmented feedback can be used to compensate for an attenuation of haptic feedback $[55,56]$. A spatial separation between the palmar surface and the environment can affect force perception [57], hence facilitating tactile sensation is considered to be of great importance in dynamic hand orthoses [58].

The design of augmented feedback signals, however, should be considered carefully. It does not always work effectively [55] and may even prove to be counterproductive [59]. Determining the ideal form of augmented feedback signals is challenging, hard to verify and in many cases related to task complexity [24]. Nonetheless, proper designs have shown potential in robot-aided rehabilitation [60].

\section{Energy \\ Energy storage}

The usage of components for energy storage is rarely reported, which is reflected by the low number of cases where this could be determined (73 out of 165). Of these cases, the method of energy storage is usually a consequence of choices in actuation, which is why electric batteries are often used because of the high use of electric/magnetic actuators. It should be noted, however, that tapping energy from a centralized system (e.g. mains electricity or compressed air systems) was not considered. It's

Table 5 Overview of included dynamic hand orthoses classified as EVA glove

\begin{tabular}{|c|c|c|c|c|c|c|}
\hline Name/ID & Country & Year range $^{a}$ & ISO abbr. & Reported function & Actuator DOF ${ }^{\mathrm{b}}$ & Wrist support ${ }^{\mathrm{b}}$ \\
\hline Shields [111] & USA & 1997 & $\mathrm{HdO}$ & power assistance & 3 & Limited (FE, RUD) \\
\hline SkilMate $[56,336]$ & Japan & $2001-2004$ & $\mathrm{HdO}$ & power assistance & 3 & N/A \\
\hline Matheson $1[22,23]$ & Australia & $2011-2012$ & WHFO & general assistance & 1 & Limited (PS, FE, RUD) \\
\hline Matheson $2[22,23]$ & Australia & $2011-2012$ & $\mathrm{FO}$ & general assistance & 2 & Limited (PS, FE, RUD) \\
\hline
\end{tabular}

a Year ranges are determined by the year span between found literature sources and my differ from the actual time of development

${ }^{\mathrm{b}}$ Actuator DOF = number of individually controlled actuators (zero means fully passive)

${ }^{c}$ Wrist can be assisted, resisted, limited or locked [29] in pronation/supination (PS), flexion/extension (FE) and radial/ulnar deviation (RUD) 
Table 6 Overview of included dynamic hand orthoses classified as haptic device

\begin{tabular}{|c|c|c|c|c|c|c|}
\hline Name/ID & Country & Year range $\mathrm{a}^{\mathrm{a}}$ & ISO abbr. & Reported function & Actuator DOF & Wrist support ${ }^{b}$ \\
\hline $\begin{array}{l}\text { SKK Hand Master } \\
{[68,337]}\end{array}$ & South Korea & 1999-2000 & $\mathrm{HdO}$ & VR feedback & 7 & N/A \\
\hline Koyama [338] & Japan & 2002 & $\mathrm{HdO}$ & VR feedback, teleoperation & 0 & $\mathrm{~N} / \mathrm{A}$ \\
\hline $\begin{array}{l}\text { Rutgers } \\
\text { Master-II-ND [70] }\end{array}$ & USA & 2002 & $\mathrm{HdO}$ & VR feedback & 4 & N/A \\
\hline $\begin{array}{l}\text { LRP hand master } \\
\text { [339] }\end{array}$ & France & 2003 & $\mathrm{HdO}$ & VR feedback & 14 & $\mathrm{~N} / \mathrm{A}$ \\
\hline Stergiopoulos [65] & France & 2003 & $\mathrm{HdO}$ & VR feedback & 2 & $\mathrm{~N} / \mathrm{A}$ \\
\hline Lelieveld $[88,340]$ & Japan & 2006 & $\mathrm{FO}$ & VR feedback & 4 & N/A \\
\hline $\begin{array}{l}\text { Nakagawara } \\
{[341,342]}\end{array}$ & Japan & $2005-2007$ & $\mathrm{HdO}$ & tele-operation & 6 & N/A \\
\hline Ryu [69] & South Korea & 2008 & WHFO & VR feedback & 3 & Not clear \\
\hline CyperGrasp [343] & USA & 2009 & $\mathrm{HdO}$ & VR feedback & 5 & N/A \\
\hline Fang $[344,345]$ & China & 2009 & $\mathrm{HdO}$ & teleoperation & 5 & N/A \\
\hline Charoenseang [346] & Thailand & 2011 & $\mathrm{HdO}$ & VR feedback & 9 & $\mathrm{~N} / \mathrm{A}$ \\
\hline Fontana $[347,348]$ & Italy & 2009-2013 & $\mathrm{HdO}$ & VR feedback, teleoperation & 6 & N/A \\
\hline Dexmo F2 $[349,350]$ & China & 2014 & $\mathrm{HdO}$ & VR feedback & 5 & $\mathrm{~N} / \mathrm{A}$ \\
\hline SPIDAR-10 [351] & Japan & 2014 & WHFO & VR feedback & 20 (+1 wrist) & $\begin{array}{l}\text { Assisted (PS) } \\
\text { Limited (FE, RUD) }\end{array}$ \\
\hline Jo $[352,353]$ & South Korea & 2013-2015 & $\mathrm{HdO}$ & VR feedback & 5 & N/A \\
\hline $\begin{array}{l}\text { SAFE Glove } \\
{[354,355]}\end{array}$ & USA & 2015 & $\mathrm{HdO}$ & VR feedback & 6 & N/A \\
\hline
\end{tabular}

a Year ranges are determined by the year span between found literature sources and my differ from the actual time of development

${ }^{\mathrm{b}}$ Actuator DOF = number of individually controlled actuators (zero means fully passive)

'Wrist can be assisted, resisted, limited or locked [29] in pronation/supination (PS), flexion/extension (FE) and radial/ulnar deviation (RUD)

usage is in many cases hard to verify from available literature and its effects on portability are covered in the mechanical domain.

The most-often used form of energy storage is with elastic energy, of which a helical spring is the most straightforward example. They are often added to realize antagonistic movement when the primary actuation or transmission method is not able to do so [61]. Other usages include applications where unidirectional and passive forces are sufficient to overcome an impairment, which is the case when compensating hyperflexion [62]. A special case of utilizing elastic energy lies in compliant structures. Aside from introducing mechanical potential energy, they can function like a mechanism and provide for an articulating and load-bearing structure. Compliant mechanisms are both efficient and inherently flexible [63], but also introduce complications in defining rotation centers and there is a careful balance between stiffness and elasticity [23].

\section{Actuation}

The most prominent result from the trends on actuation components is the large amount (113 out of 165) of devices that use a form of electromagnetic actuation. DC motors have the upper hand within this group, but reasonings behind this choice are hard to retrieve. Reported arguments include the increased possibilities for both position and torque control [64], high mechanical bandwidth [65] and general performance in the torquevelocity space [13]. Such properties appear most useful in applications where variability in control strategies is sought-after or when high-frequent perturbations or interactions need to be applied. For applications that focus more on general assistance, the lower torque-tospeed ratios of DC motors need to be reduced to coincide with the higher ratio demands for human movement. As a result, gearheads are added to reduce the high speeds, adding backlash and reducing inherent backdrivability of the device [65]. An interesting development here lies in the twisted string actuation system, which reaches high reduction ratios by twisting strands on one end and creating linear motion on the other end $[66,67]$. Alternatively, ceramic piezoelectricity as used in ultrasonic motors can also provide for a more suitable torque-to-speed ratio. They are silent, have high powerto-weight ratio and are able to facilitate free motion [68]. However, they also require high voltages [69] and show hysteresis [68].

An often mentioned substitute for electromagnetic actuation, is the use of pneumatic actuation. They are 
intrinsically compliant, lightweight, act similar to natural muscles and high power-to-weight ratios are reported [23, $58,61,70-74]$. Still, no commercial pneumatically powered prosthesis or orthosis exists to date to our knowledge. The main reported drawbacks are difficulties in control, expensive components and low bandwidth [69, 71, 75]. The stated arguments, however, impress as ambiguous due to vague definitions and lack of comparison with design requirements. For example, definitions for powerto-weight ratios are often unclear [76] and a distinction can be made between high- and low-force bandwidth [77]. Concerning the latter, human force control operates at around $7 \mathrm{~Hz}$ [78] and rehabilitation does not necessarily require high bandwidths [4], displaying values that do appear within range of pneumatic actuators.

Other methods of actuation appear to be more experimental or impractical. The natural muscle can be used as an actuator and is the crux in body-powered prosthetics. Although applicable for local impairments at the hand, this becomes less practical in orthotics when the muscle itself requires support, as this would add the need for yet another force amplifier. Active polymers appear more promising, being thin, lightweight, compliant and able to perform both sensing and actuation. However, in [79], it was stated that fundamental enhancements would be required for feasible use in upper limb prosthetics. Similar to shape memory alloys [80-82], forces are generally low and take time to build up (i.e. low bandwidths), which results in the need for large stacked configurations $[83,84]$.

\section{Mechanical}

\section{Transmission}

No existing studies were found that presented a form of categorization on transmission components usable for dynamic hand orthoses. Consequently, the results and interpretation are based on (and limited by) a categorization from the authors' perspective. Some approaches can be considered as a direct consequence from design choices in the energy domain. For example, gears are most often used to alter DC motor speeds and compliant mechanisms integrate both energy storage and transmission. Other approaches are more a result of choice in mechanism, where $n$-bar linkages are well-known methods of facilitating path trajectories. Nonetheless, additional notable approaches can be reviewed and coupled with reported argumentations.

The most arguments are reported for pulley-cable and Bowden cable systems. Pulley-cable systems are spatially constrained and require a continuous control of cable tension to maintain traction on the pulleys $[13,85,86]$. Bowden cable systems, on the other hand, are a type of cable-conduit and are essentially flexible, but introduce variable and high friction forces dependent on curvature
[87-91]. Nonetheless, both cable systems most resemble the tendon mechanism in the natural hand [61, 9297] and are often an effective method of proximally placing the actuators to reduce the inertia of moving parts $[13,85,96,98,99]$.

Fluidic transmissions are generally more efficient for larger channel diameters, which could explain the low use in dynamic hand orthoses (3 out of 165). Despite this, hydraulic transmissions remain promising at similar scales [100] and are able to provide a more efficient alternative compared to a similar cable mechanism [101]. In comparison with hydraulics, a pneumatic transmission can offer faster responses due to the use of low-viscosity fluids $[69,100]$, but is not encountered in the included dynamic hand orthoses.

\section{Mechanism}

The alignment of anatomical and mechanical joints is the essence of many mechanical design papers on hand orthoses, which is especially the case for exoskeletonbased devices [4]. Misalignments may cause numerous sources of discomfort to the user, resulting in possible frustration by the user, rejection of the device and eventual hindrance in the rehabilitation program [102]. Even tissue damage can occur, where pressure sores, joint dislocations or cartilage damage are among the possibilities depending on the user $[102,103]$. The main design challenges lie in limited available space, differences in hand sizes and coping with the compliance of skin tissue. Additionally, the rotation axis of a finger joint is not constant [104], i.e. polycentric. Despite the latter, however, almost half of the dynamic hand orthoses use monocentric rotation (79 out of 165). This includes the more straightforward hinge joints [61], but also those that use a virtual center of rotation with fixed rotation axis (e.g. concentric rotation in [105]). In these cases, the rotation centers need to be manually aligned and results in a time-consuming process for different hand sizes [90]. This is where self-aligning joint centers are often-used alternatives. They are able to adapt to various hand sizes [44] and prevent strong discomfort for the user [96, 98]. Self-aligning mechanisms are essentially polycentric and conform to whatever rotation the anatomical joint imposes. Moreover, efficiency is increased as the device finds less resistance from the user.

End-effector-based devices omit the constriction of joint movement by only moving the most distal end of the fingers [4], forming a kinematic chain with the ground. This makes it advantageous over exoskeletonbased devices [106], but also less suitable for applications with more strict design constraints on portability (i.e. home rehabilitation and daily assistive tools).

A general trend towards simplification of the hand kinematics can be seen. This includes the introduction of 
couplings by force (i.e. underactuation) and by motion (i.e. constraints) in order to reduce the complexity of the device. These methods are similar to the mechanical couplings and control synergies that exist in the natural hand [104, 107]. This concept can be generalized under the term functional degrees of freedom (fDOF) [108], which means that complex movement patterns can be generalized and achieved by less complex actuation strategies. This is a viable approach for dynamic hand orthoses as complex multi-DOF movements are unnecessary for many rehabilitation purposes [60, 109] and grasping patterns that are used during ADL can be generalized [110]. Underactuation, in particular, is a popular method as it reduces weight and complexity $[65,74,86,93,97,109,111]$ and it facilitates passive adaptation for better object manipulation $[86,94]$. From the results, it appears that intrafinger (i.e. across joints) underactuation is preferred, as opposed to interfinger (i.e. across fingers) underactuation which is an upcoming feature and allows passive adaptation to 3D objects [93, 112].

\section{Conclusion}

A high quantity of dynamic hand orthoses was gathered and shows that their development is becoming increasingly prevalent. A framework was developed in an attempt to collectively analyze the diverse solution space, whose general methodology can be used for other mechatronic systems that interact with the human. The investigated solution space reveals several outliers, for example the preference for EMG or force/motion control and electromagnetic actuation. There are also less-used solutions that do seem feasible, like compliant mechanisms, fluidic transmission/actuation and interfinger underactuation. By no means is the framework complete, as more branches can be added to the tree diagrams that expand and extend further into the solution space at increased level of detail. Even so, a comprehensive analysis was performed that can be used as a general exploration on mechatronic design of dynamic hand orthotics-and possibly other related fields as well.

\section{Additional file}

Additional file 1: An Excel spreadsheet which contains obtained information from all devices and categorization into the presented framework. (XLSX $143 \mathrm{~kb})$

\section{Abbreviations}

DMD, duchenne musculuar dystrophy; ADL, activities of daily living; CPM, continuous passive motion; $\mathrm{VR}$, virtual reality; EVA, extra-vehicular activity; DOF, degree of freedom; fDOF, functional degrees of freedom; EEG, electroencephalography; PNI, peripheral nerve interface; EMG, electromyography; MMG, mechanomyography; FMG, force myography

\section{Funding}

This research is part of the Symbionics program, which is partially supported by the Dutch Technology foundation STW (\#13524 and \#13525), Hankamp Rehabilitation (Enschede, NL), Hocoma (Volketswil, CH), TMSi (Oldenzaal, NL), Moog (Nieuw Vennep, NL), FESTO (Delft, NL), and multiple Duchenne foundations (NL \& USA). STW is part of the Netherlands Organization for Scientific Research (NWO), which is partly funded by the Ministry of Economic Affairs.

\section{Availability of supporting data}

The dataset supporting the conclusions of this article is included within the article (and its Additional file 1).

\section{Authors' contributions}

RAB performed the main review of literature, conception of the framework, processing of the data and drafting of the manuscript. CJWH and TS made substantial contributions to the review of literature, structure of the study and were actively involved in the writing process of the manuscript. KN provided for essential contributions regarding intention detection systems and was also actively involved in the writing process. JLH, AHAS and DHP oversaw the project, provided important content and made critical revisions to the manuscript. All authors read and approved the final manuscript.

\section{Competing interests}

The authors declare that they have no competing interests.

\section{Author details}

${ }^{1}$ Department of Biomechanical Engineering, Delft University of Technology, 2628 CD Delft, Mekelweg 2, The Netherlands. ${ }^{2}$ Department of Biomechanical Engineering, University of Twente, 7522 NB Enschede, Drienerlolaan 5, The Netherlands. ${ }^{3}$ Department of Precision and Microsystems Engineering, Delft University of Technology, 2628 CD Delft, Mekelweg 2, The Netherlands. ${ }^{4}$ Department of Physical Therapy and Human Movement Sciences, Northwestern University, 645 N. Michigan Ave. Suite 1100, 60611 Chicago, IL, USA.

Received: 5 February 2016 Accepted: 10 June 2016

Published online: 29 June 2016

\section{References}

1. Heo P, Gu GM, Lee SJ, Rhee K, Kim J. Current hand exoskeleton technologies for rehabilitation and assistive engineering. Int J Precis Eng Manuf. 2012;13(5):807-24. doi:10.1007/s12541-012-0107-2.

2. Balasubramanian S, Klein J, Burdet E. Robot-assisted rehabilitation of hand function. Curr Opin Neurol. 2010;23(6):661-70. doi:10.1097/WCO.0b013e32833e99a4.

3. Basteris A, Nijenhuis SM, Stienen AHA, Buurke JH, Prange GB, Amirabdollahian F. Training modalities in robot-mediated upper limb rehabilitation in stroke: a framework for classification based on a systematic review. J NeuroEngineering Rehabil. 2014;11(1):111. doi:10.1186/1743-0003-11-111

4. Maciejasz P, Eschweiler J, Gerlach-Hahn K, Jansen-Troy A, Leonhardt S. A survey on robotic devices for upper limb rehabilitation. J NeuroEngineering Rehabil. 2014;11(1):3. doi:10.1186/1743-0003-11-3.

5. Kwakkel G, Kollen BJ, Krebs HI. Effects of robot-assisted therapy on upper limb recovery after stroke: a systematic review. Neurorehabil Neural Repair. 2008;22(2):111-21. doi:10.1177/1545968307305457.

6. Janssen MMHP, Bergsma A, Geurts ACH, de Groot IJM. Patterns of decline in upper limb function of boys and men with DMD: an international survey. J Neurol. 2014;261(7):1269-1288. doi:10.1007/s00415-014-7316-9.

7. Lobo-Prat J, Kooren PN, Stienen AHA, Herder JL, Koopman BFJM, Veltink $\mathrm{PH}$. Non-invasive control interfaces for intention detection in active movement-assistive devices. J NeuroEngineering Rehabil. 2014;11(1):168. doi:10.1186/1743-0003-11-168.

8. Herr H. Exoskeletons and orthoses: classification, design challenges and future directions. J NeuroEngineering Rehabil. 2009;6(1):21. doi:10.1186/1743-0003-6-21

9. Gopura RARC, Bandara DSV, Kiguchi K, Mann GKI. Developments in hardware systems of active upper-limb exoskeleton robots: A review. Robot Auton Syst. 2015. doi:10.1016/j.robot.2015.10.001. 
10. ISO/TC 168: Prosthetics and orthotics - vocabulary - part 1: General terms for external limb prostheses and external orthoses. Technical Report 8549-1:1989. Geneva, Switzerland: International Organization for Standardization; 1989.

11. ISO/TC 168: Prosthetics and orthotics - vocabulary - part 3: Terms relating to external orthoses. Technical Report 8549-3:1989. Geneva, Switzerland: International Organization for Standardization; 1989.

12. Fiorilla AE, Nori F, Masia L, Sandini G. Finger impedance evaluation by means of hand exoskeleton. Ann Biomed Eng. 2011;39(12):2945-954. doi:10.1007/s10439-011-0381-7.

13. Jones CL, Wang F, Morrison R, Sarkar N, Kamper DG. Design and development of the cable actuated finger exoskeleton for hand rehabilitation following stroke. IEEE/ASME Transac Mechatron. 2014;19(1):131-40. doi:10.1109/TMECH.2012.2224359.

14. Prange GB, Jannink MJA, Groothuis-Oudshoorn CGM, Hermens HJ, Ijzerman MJ. Systematic review of the effect of robot-aided therapy on recovery of the hemiparetic arm after stroke. J Rehab Res Dev. 2006;43(2):171-84. doi:10.1682/JRRD.2005.04.0076.

15. Mehrholz J, Platz T, Kugler J, Pohl M. Electromechanical and robot-assisted arm training for improving arm function and activities of daily living after stroke. Cochrane Database Syst Rev. 2008:4:006876. doi:10.1002/14651858.CD006876.pub2.

16. Timmermans AAA, Seelen HAM, Willmann RD, Kingma $H$. Technology-assisted training of arm-hand skills in stroke: concepts on reacquisition of motor control and therapist guidelines for rehabilitation technology design. J Neuroengineering Rehabil. 2009;6(1):1. doi:10.1186/1743-0003-6-1.

17. Reinkensmeyer DJ, Boninger ML. Technologies and combination therapies for enhancing movement training for people with a disability. J NeuroEngineering Rehabil. 2012;9(1):17. doi:10.1186/1743-0003-9-17.

18. Plettenburg DH. Upper extremity prosthetics: Current Status \& Evaluation, 1st ed. Delft: VSSD; 2006. ISBN: 978-90-71301-75-9.

19. Polygerinos P, Wang Z, Galloway KC, Wood RJ, Walsh CJ. Soft robotic glove for combined assistance and at-home rehabilitation. Robot Auton Syst. 2015;73:135-43. doi:10.1016/j.robot.2014.08.014.

20. Mali U, Munih M. HIFE-haptic interface for finger exercise. IEEE/ASME Transac Mechatron. 2006;11(1):93-102. doi:10.1109/TMECH.2005.863363.

21. Festo AG \& Co. KG. ExoHand Brochure. 2012. http://www.festo.com/net/ SupportPortal/Files/156734/Brosch_FC_ExoHand_EN_lo.pdf. Accessed 19 Oct 2015

22. Matheson E, Brooker G. Assistive Rehabilitation Robotic Glove. In: Proceedings of Australasian Conference on Robotics and Automation. Melbourne; 2011.

23. Matheson E, Brooker G. Augmented robotic device for EVA hand manoeuvres. Acta Astronautica. 2012;81(1):51-61. doi:10.1016/j.actaastro.2012.06.006.

24. Sigrist R, Rauter G, Riener R, Wolf P. Augmented visual, auditory, haptic, and multimodal feedback in motor learning: A review. Psychon Bull Rev. 2013;20(1):21-53. doi:10.3758/s13423-012-0333-8.

25. Zupan M, Ashby MF, Fleck NA. Actuator classification and selection the development of a database. Adv Eng Mater. 2002;4(12):933-40. doi:10.1002/adem.200290009.

26. Poole AD, Booker JD. Design methodology and case studies in actuator selection. Mech Mach Theory. 2011;46(5):647-61. doi:10.1016/j.mechmachtheory.2010.12.009.

27. Abbink DA, Mulder M, Boer ER. Haptic shared control: smoothly shifting control authority? Cogn Tech Work. 2012;14(1):19-28. doi:10.1007/s10111-011-0192-5.

28. Cornell University: Reuleaux Collection of Kinematic Mechanisms. http:// kmoddl.library.cornell.edu/model.php?m=reuleaux. Accessed 19 Nov 2015.

29. ISO/TC 168: Prosthetics and orthotics - categorization and description of external orthoses and orthotic components. Technical Report ISO 13404:2007. Geneva, Switzerland: International Organization for Standardization; 2007.

30. Takahashi CD, Der-Yeghiaian L, Le VH, Cramer SC. A robotic device for hand motor therapy after stroke. In: 2005 IEEE 9th International Conference on Rehabilitation Robotics (ICORR). Chicago, IL; 2005. p. 17-20. doi:10.1109/ICORR.2005.1501041.
31. Lambercy O, Dovat L, Gassert R, Burdet E, Teo CL, Milner T. A haptic knob for rehabilitation of hand function. IEEE Transac Neural Syst Rehabil Eng. 2007;15(3):356-66. doi:10.1109/TNSRE.2007.903913.

32. Ates S, Leon B, Basteris A, Nijenhuis SM, Nasr N, Sale P, Cesario A, Amirabdollahian F, Stienen AHA. Technical evaluation of and clinical experiences with the SCRIPT passive wrist and hand orthosis. In: 2014 7th International Conference on Human System Interactions (HSI). Costa da Caparica; 2014. p. 188-93. doi:10.1109/HSI.2014.6860472.

33. Sauerbruch F. Die Willkürlich Bewegbare Künstliche Hand: Eine Anleitung Für Chirurgen Und techniker. Berlin: Julius Springer; 1916. ISBN: 978-3642649196.

34. Weir RF, Heckathorne CW, Childress DS. Cineplasty as a control input for externally powered prosthetic components. J Rehabil Res Dev. 38(4): 357-63.

35. Ison M, Artemiadis P. The role of muscle synergies in myoelectric control: trends and challenges for simultaneous multifunction control. J Neural Eng. 2014;11(5):051001. doi:10.1088/1741-2560/11/5/051001.

36. Pedrocchi A, Ferrante S, Ambrosini E, Gandolla M, Casellato C, Schauer T, Klauer C, Pascual J, Vidaurre C, Gföhler M, Reichenfelser W, Karner J, Micera S, Crema A, Molteni F, Rossini M, Palumbo G, Guanziroli E, Jedlitschka A, Hack M, Bulgheroni M, D’Amico E, Schenk P, Zwicker S, Duschau-Wicke A, Miseikis J, Graber L, Ferrigno G. MUNDUS project: MUltimodal Neuroprosthesis for daily Upper limb Support. J NeuroEngineering Rehabil. 2013;10:66. doi:10.1186/1743-0003-10-66.

37. Wege A, Zimmermann A. Electromyography sensor based control for a hand exoskeleton. In: 2007 IEEE International Conference on Robotics and Biomimetics (ROBIO). Sanya; 2007. p. 1470-1475. doi:10.1109/ROBIO.2007.4522381.

38. Takagi M, Iwata K, Takahashi Y, Yamamoto SI, Koyama H, Komeda T. Development of a grip aid system using air cylinders. In: 2009 IEEE International Conference on Robotics and Automation (ICRA). Kobe; 2009. p. 2312-317. doi:10.1109/ROBOT.2009.5152246.

39. Kadowaki Y, Noritsugu T, Takaiwa M, Sasaki D, Kato M. Development of soft power-assist glove and control based on human intent. J Robot Mechatron. 23(2):281-91.

40. Ochoa JM, Kamper DG, Listenberger M, Lee SW. Use of an electromyographically driven hand orthosis for training after stroke. In: 2011 IEEE International Conference on Rehabilitation Robotics (ICORR). Zurich; 2011. p. 1-5. doi:10.1109/ICORR.2011.5975382.

41. Sasaki D, Noritsugu T, Takaiwa M, Konishi H. Control method based on EMG for power assist glove using self-organizing maps. Int J Autom Technol. 2014;8(2):177-85.

42. Corbett EA, Perreault EJ, Kuiken TA. Comparison of electromyography and force as interfaces for prosthetic control. J Rehabil Res Dev. 2011;48(6):629-42. doi:10.1682/JRRD.2010.03.0028.

43. Lobo-Prat J, Keemink AQL, Stienen AHA, Schouten AC, Veltink PH, Koopman BFJM. Evaluation of EMG, force and joystick as control interfaces for active arm supports. J Neuroengineering Rehabil. 2014;11(1):68. doi:10.1186/1743-0003-11-68.

44. Ueki S, Kawasaki H, Ito S, Nishimoto Y, Abe M, Aoki T, Ishigure Y, Ojika T, Mouri T. Development of a hand-assist robot with multi-degrees-of-freedom for rehabilitation therapy. IEEE/ASME Transac Mechatron. 2012;17(1):136-46. doi:10.1109/TMECH.2010.2090353.

45. Bae JH, Kim YM, Moon I. Wearable hand rehabilitation robot capable of hand function assistance in stroke survivors. In: 2012 4th IEEE RAS \& EMBS International Conference on Biomedical Robotics and Biomechatronics (BioRob). Rome; 2012. p. 1482-1487. doi:10.1109/BioRob.2012.6290736.

46. Otsuka T, Sankai Y. Development of exo-finger for grasp-assistance. In: SCIS \& ISIS. Okayama; 2010. p. 410-5. doi:10.14864/softscis.2010.0.410.0.

47. King CE, Dave KR, Wang PT, Mizuta M, Reinkensmeyer DJ, Do AH, Moromugi S, Nenadic Z. Performance Assessment of a Brain-Computer Interface Driven Hand Orthosis. 2014. doi:10.1007/s10439-014-1066-9.

48. Cruz EG, Kamper DG. Use of a novel robotic interface to study finger motor control. Ann Biomed Eng. 2010;38(2):259-68. doi:10.1007/s10439-009-9845-4.

49. Loureiro RCV, Harwin WS. Reach and grasp therapy: design and control of a 9-DOF robotic neuro-rehabilitation system. In: 2007 IEEE 10th International Conference on Rehabilitation Robotics (ICORR). Noordwijk; 2007. p. 757-63. doi:10.1109/ICORR.2007.4428510.

50. Sarakoglou I, Tsagarakis NG, Caldwell DG. Occupational and physical therapy using a hand exoskeleton based exerciser. In: 2004 IEEE/RSJ 
International Conference on Intelligent Robots and Systems (IROS), vol. 3. Sendai; 2004. p. 2973-978. doi:10.1109/IROS.2004.1389861.

51. Benjuya N, Kenney SB. Myoelectric hand orthosis. J Prosthetics Orthot. 2(2):149-54.

52. Wolbrecht ET, Reinkensmeyer DJ, Perez-Gracia A. Single degree-of-freedom exoskeleton mechanism design for finger rehabilitation. In: 2011 IEEE International Conference on Rehabilitation Robotics (ICORR). Zurich; 2011. p. 1-6. doi:10.1109/ICORR.2011.5975427.

53. Cordo P, Wolf S, Lou JS, Bogey R, Stevenson M, Hayes J, Roth E. Treatment of severe hand impairment following stroke by combining assisted movement, muscle vibration, and biofeedback. J Neurol Phys Ther. 2013;37(4):194-203. doi:10.1097/NPT.0000000000000023.

54. Backus D, Cordo P, Gillott A, Kandilakis C, Mori M, Raslan AM. Assisted movement with proprioceptive stimulation reduces impairment and restores function in incomplete spinal cord injury. Arch Phys Med Rehabil. 2014;95(8):1447-1453. doi:10.1016/j.apmr.2014.03.011.

55. Watanabe K, Morishita H, Mori T, Sato T. A Prototype of Index-Finger PIP Joint Motion Amplifier for Assisting Patients with Impaired Hand Mobility. In: 2007 IEEE International Conference on Robotics and Automation (ICRA). Rome; 2007. p. 4146-151. doi:10.1109/ROBOT.2007.364116.

56. Yamada Y, Morizono T, Sato K, Shibuya H, Shimohira T, Umetani $Y$, Yoshida T, Aoki S. Proposal of a SkilMate Hand and its component technologies for extravehicular activity gloves. Adv Robot. 2004;18(3): 269-84. doi:10.1163/156855304322972440.

57. Jones $L A$, Piateski E. Contribution of tactile feedback from the hand to the perception of force. Exp Brain Res. 2006;168:298-302. doi:10.1007/s00221-005-0259-8.

58. Heo P, Kim J. Power-assistive finger exoskeleton with a palmar opening at the fingerpad. IEEE Transac Biomed Eng. 2014;61(11):2688-697. doi:10.1109/TBME.2014.2325948.

59. Rosati G, Rodà A, Avanzini F, Masiero S. On the role of auditory feedback in robot-assisted movement training after stroke: Review of the literature. Comput Intell Neurosci. 2013;2013:1-15. doi:10.1155/2013/586138.

60. Rosati G, Cenci S, Boschetti G, Zanotto D, Masiero S. Design of a single-dof active hand orthosis for neurorehabilitation. In: 2009 IEEE International Conference on Rehabilitation Robotics (ICORR). Kyoto; 2009. p. 161-6. doi:10.1109/ICORR.2009.5209552.

61. Tjahyono AP, Aw KC, Devaraj H, Surendra WA, Haemmerle E, Travas-Sejdic J. A five-fingered hand exoskeleton driven by pneumatic artificial muscles with novel polypyrrole sensors. Ind Robot Int J. 2013:40(3):251-60. doi:10.1108/01439911311309951.

62. Brokaw EB, Black I, Holley RJ, Lum PS. Hand Spring Operated Movement Enhancer (HandSOME): a portable, passive hand exoskeleton for stroke rehabilitation. IEEE Transac Neural Syst Rehabil Eng. 2011;19(4): 391-9. doi:10.1109/TNSRE.2011.2157705

63. Arata J, Ohmoto K, Gassert R, Lambercy O, Fujimoto H, Wada I. A new hand exoskeleton device for rehabilitation using a three-layered sliding spring mechanism. In: 2013 IEEE International Conference on Robotics and Automation (ICRA). Karlsruhe; 2013. p. 3902-907. doi:10.1109/ICRA.2013.6631126.

64. Schabowsky CN, Godfrey SB, Holley RJ, Lum PS. Development and pilot testing of HEXORR: hand EXOskeleton rehabilitation robot. J NeuroEngineering Rehabil. 2010;7(1):36. doi:10.1186/1743-0003-7-36.

65. Stergiopoulos $P$, Fuchs $P$, Laurgeau C. Design of a 2-finger hand exoskeleton for VR grasping simulation. In: Eurohaptics. Dublin; 2003. p. 80-93.

66. Würtz T, May C, Holz B, Natale C, Palli G, Melchiorri C. The twisted string actuation system: modeling and control. In: 2010 IEEE/ASME International Conference on Advanced Intelligent Mechatronics. Montreal, ON, Canada; 2010. p. 1215-1220. doi:10.1109/AIM.2010. 5695720.

67. Palli G, Natale C, May C, Melchiorri C, Würtz T. Modeling and control of the twisted string actuation system. IEEE/ASME Transac Mechatron. 2013;18(2):664-73. doi:10.1109/TMECH.2011.2181855.

68. Choi BH, Choi HR. SKK Hand Master-hand exoskeleton driven by ultrasonic motors. In: 2000 IEEE/RSJ International Conference on Intelligent Robots and Systems (IROS), vol. 2. Takamatsu; 2000. p. 1131-1136. doi:10.1109/IROS.2000.893171.

69. Ryu D, Moon KW, Nam H, Lee Y, Chun C, Kang S, Song JB. Micro hydraulic system using slim artificial muscles for a wearable haptic glove.
In: 2008 IEEE/RSJ International Conference on Intelligent Robots and Systems (IROS). Nice; 2008. p. 3028-033. doi:10.1109/IROS.2008.4651159.

70. Bouzit M, Burdea G, Popescu G, Boian R. The Rutgers Master II - New design force-feedback glove. IEEE/ASME Transac Mechatron. 2002;7(2): 256-63. doi:10.1109/TMECH.2002.1011262.

71. Xing K, Xu Q, He J, Wang Y, Liu Z, Huang X. A wearable device for repetitive hand therapy. In: 2nd Biennial IEEE RAS \& EMBS International Conference on Biomedical Robotics and Biomechatronics (BioRob). Scottsdale, AZ; 2008. p. 919-23. doi:10.1109/BIOROB.2008.4762789.

72. Sun Z, Miao X, Li X. Design of a bidirectional force feedback dataglove based on pneumatic artificial muscles. In: 2009 International Conference on Mechatronics and Automation. Changchun; 2009. p. 1767-1771. doi:10.1109/ICMA.2009.5246223.

73. Tadano K, Akai M, Kadota K, Kawashima K. Development of grip amplified glove using bi-articular mechanism with pneumatic artificial rubber muscle. In: 2010 IEEE International Conference on Robotics and Automation (ICRA). Anchorage, AK; 2010. p. 2363-368. doi:10.1109/ROBOT.2010.5509393.

74. Surendra WA, Tjahyono AP, Aw KC. Portable and Wearable Five-Fingered Hand Assistive Device. In: 2012 19th International Conference on Mechatronics and Machine Vision in Practice (M2VIP). Auckland; 2012. p. 431-5.

75. Wu J, Huang J, Wang Y, Xing K. A Wearable Rehabilitation Robotic Hand Driven by PM-TS Actuators. In: Lecture Notes in Computer Science vol. 6425. Shanghai; 2010. p. 440-450. doi:10.1007/978-3-642-16587-0_41.

76. Plettenburg DH. Pneumatic actuators: A comparison of energy-to-mass ratio's. In: 2005 IEEE 9th International Conference on Rehabilitation Robotics (ICORR). Chicago, IL; 2005. p. 545-9. doi:10.1109/ICORR.2005.1502022.

77. Stienen AHA, Hekman EEG, Braak HT, Aalsma AMM, Van Der Helm FCT, Van Der Kooij H. Design of a rotational hydroelastic actuator for a powered exoskeleton for upper limb rehabilitation. IEEE Transac Biomed Eng. 2010;57(3):728-35. doi:10.1109/TBME.2009.2018628.

78. Tan HZ, Eberman B, Srinivasan MA, Cheng B. Human factors for the design of force-reflecting haptic interfaces. Am Soc Mech Eng Dynamic Syst Control Div. 1994;55-1:353-9.

79. Biddiss E, Chau T. Dielectric elastomers as actuators for upper limb prosthetics: Challenges and opportunities. Med Eng Phys. 2008;30(4): 403-18. doi:10.1016/j.medengphy.2007.05.011.

80. Makaran JB, Dittmer DK, Buchal RO, MacArthur DB. The SMART(R) Wrist-Hand Orthosis (WHO) for quadriplegic patients. J Prosthetics Orthot. 5(3):3-6.

81. Tang T, Zhang D, Xie T, Zhu X. An exoskeleton system for hand rehabilitation driven by shape memory alloy. In: 2013 IEEE International Conference on Robotics and Biomimetics (ROBIO). Shenzhen; 2013. p. 756-61. doi:10.1109/ROBIO.2013.6739553.

82. Zheng DY, Luo M, Yang SS. Design of a mechanical exoskeleton system for improving hand-gripping force. Adv Mater Res. 2013;663:708-12. doi:10.4028/www.scientific.net/AMR.663.708.

83. Aw KC, McDaid AJ. Bio-applications of ionic polymer metal composite transducers. Smart Mater Struct. 2014;23(7):074005. doi:10.1088/0964-1726/23/7/074005.

84. Lee DW, Lee SJ, Yoon BR, Jho JY, Rhee K. Preliminary study on analysis of pinching motion actuated by electro-active polymers. In J Mech Aerosp Ind Mechatron Eng. 8(5):922-4.

85. In H, Cho KJ. Evaluation of the antagonistic tendon driven system for SNU Exo-Glove. In: 2012 9th International Conference on Ubiquitous Robots and Ambient Intelligence (URAI). Daejeon; 2012. p. 507-9.

86. Iqbal J, Khan H, Tsagarakis NG, Caldwell DG. A novel exoskeleton robotic system for hand rehabilitation-conceptualization to prototyping. Biocybernetics Biomed Eng. 2014;34(2):79-89. doi:10.1016/j.bbe.2014.01.003.

87. Wege A, Hommel G. Development and control of a hand exoskeleton for rehabilitation of hand injuries. In: 2005 IEEE/RSJ Int Conf Intell Robots and Syst (IROS). Edmonton, AB; 2005. p. 3046-051. doi:10.1109/IROS.2005.1545506.

88. Lelieveld MJ, Maeno T, Tomiyama T. Design and development of two concepts for a 4 DOF portable haptic interface with active and passive multi-point force feedback for the index finger. In: 2006 ASME International Design Engineering Technical Conference (DETC). Philadelphia, PA; 2006. p. 547-56. doi:10.1115/DETC2006-99111. 
89. Masia L, Krebs HI, Cappa P, Hogan N. Design and characterization of hand module for whole-arm rehabilitation following stroke. IEEE/ASME Transac Mechatron. 2007;12(4):399-407. doi:10.1109/TMECH.2007.901928.

90. Fu Y, Wang P, Wang S. Development of a multi-DOF exoskeleton based machine for injured fingers. In: 2008 IEEE/RSJ Int Conf Intell Robots Syst(IROS). Nice; 2008. p. 1946-1951. doi:10.1109/IROS.2008.4651208.

91. Li J, Zheng R, Zhang Y, Yao J. iHandRehab: An interactive hand exoskeleton for active and passive rehabilitation. In: 2011 IEEE Int Conf Rehabil Robotics (ICORR). Zurich; 2011. p. 1-6. doi:10.1109/ICORR.2011.5975387.

92. Baker MD, McDonough MK, McMullin EM, Swift M, BuSha BF. Orthotic hand-assistive exoskeleton. In: 2011 IEEE 37th Annual Northeast Bioengineering Conference (NEBEC). Troy, NY; 2011. p. 1-2. doi:10.1109/NEBC.2011.5778523.

93. In H, Cho KJ, Kim K, Lee BS. Jointless structure and under-actuation mechanism for compact hand exoskeleton. In: 2011 IEEE International Conference on Rehabilitation Robotics (ICORR). Zurich; 2011. p. 1-6. doi:10.1109/ICORR.2011.5975394.

94. Nilsson M, Ingvast J, Wikander J, Von Holst H. The Soft Extra Muscle system for improving the grasping capability in neurological rehabilitation. In: 2012 IEEE EMBS Conference on Biomedical Engineering and Sciences (IECBES). Langkawi; 2012. p. 412-7. doi:10.1109/IECBES.2012.6498090.

95. Weiss P, Heyer L, Munte TF, Heldmann M, Schweikard A, Maehle E. Towards a parameterizable exoskeleton for training of hand function after stroke. In: 2013 IEEE International Conference on Rehabilitation Robotics (ICORR). Seattle, WA; 2013. p. 1-6. doi:10.1109/ICORR.2013.6650505.

96. Cempini M, Cortese M, Vitiello N. A powered finger-thumb wearable hand exoskeleton with self-aligning joint axes. IEEE/ASME Transactions on Mechatronics. 2014;20(2):705-16. doi:10.1109/TMECH.2014.2315528.

97. Lee SW, Landers KA, Park HS. Development of a biomimetic hand exotendon device (BiomHED) for restoration of functional hand movement post-stroke. IEEE Transac Neural Syst Rehabil Eng. 2014;22(4): 886-98. doi:10.1109/TNSRE.2014.2298362.

98. Chiri A, Vitiello N, Giovacchini F, Roccella S, Vecchi F, Carrozza MC. Mechatronic design and characterization of the index finger module of a hand exoskeleton for post-stroke rehabilitation. IEEE/ASME Transac Mechatron. 2012;17(5):884-94. doi:10.1109/TMECH.2011.2144614.

99. Delph II MA, Fischer SA, Gauthier PW, Luna CHM, Clancy EA, Fischer GS. A soft robotic exomusculature glove with integrated sEMG sensing for hand rehabilitation. In: 2013 IEEE Int Conf Rehabil Robotics (ICORR). Seattle, WA; 2013. p. 1-7. doi:10.1109/ICORR.2013.6650426.

100. Whitney JP, Glisson MF, Brockmeyer EL, Hodgins JK. A low-friction passive fluid transmission and fluid-tendon soft actuator. In: 2014 IEEE/RSJ International Conference on Intelligent Robots and Systems (IROS). Chicago, IL, USA; 2014. p. 2801-808 doi:10.1109/IROS.2014.6942946

101. Smit G, Plettenburg DH, van der Helm FCT. Design and evaluation of two different finger concepts for body-powered prosthetic hand. J Rehabil Res Dev. 2013;50(9):1253-1266. doi:10.1682/JRRD.2012.12.0223.

102. Meyer CM, Shrosbree RD, Abrahams DL. A method of rehabilitating the C6 tetraplegic hand. Paraplegia. 1979;17:170-5. doi:10.1038/sc.1979.35.

103. Schiele A, van der Helm FCT. Kinematic design to improve ergonomics in human machine interaction. IEEE Transac Neural Syst Rehabil Eng. 2006;14(4):456-69. doi:10.1109/TNSRE.2006.881565.

104. Gustus A, Stillfried G, Visser J, Jörntell H, van der Smagt P. Human hand modelling: kinematics, dynamics, applications. Biol Cybern. 2012;106(11-12):741-55. doi:10.1007/s00422-012-0532-4.

105. Ho NSK, Tong KY, Hu XL, Fung KL, Wei XJ, Rong W, Susanto EA. An EMG-driven exoskeleton hand robotic training device on chronic stroke subjects: Task training system for stroke rehabilitation. In: 2011 IEEE Int Conf Rehabil Robotics (ICORR). Zurich; 2011. p. 1-5. doi:10.1109/ICORR.2011.5975340.

106. Yeong CF, Melendez-Calderon A, Gassert R, Burdet E. ReachMAN: A personal robot to train reaching and manipulation. In: 2009 IEEE/RSJ International Conference on Intelligent Robots and Systems (IROS). St. Louis, MO; 2009. p. 4080-085. doi:10.1109/ROS.2009.5354837.

107. Santello M, Flanders M, Soechting JF. Postural hand synergies for tool use. J Neurosci. 18(23):10105-10115.
108. Li ZM, Tang J. Coordination of thumb joints during opposition. $J$ Biomechan. 2007;40(3):502-10. doi:10.1016/j.jbiomech.2006.02.019.

109. Ertas $I H$, Hocaoglu E, Patoglu V. AssistOn-Finger: an under-actuated finger exoskeleton for robot-assisted tendon therapy. Robotica. 2014:32(08):1363-1382. doi:10.1017/\$0263574714001957.

110. Napier JR. The prehensile movements of the human hand. J Bone Joint Surgery (British Volume). 38-B(4):902-13.

111. Shields BL, Main JA, Peterson SW, Strauss AM. An anthropomorphic hand exoskeleton to prevent astronaut hand fatigue during extravehicular activities. IEEE Transac Syst Man Cybernet Part A: Syst Humans. 1997;27(5):668-73. doi:10.1109/3468.618265.

112. Smit G, Plettenburg DH, van der Helm FCT. The lightweight Delft Cylinder Hand, the first multi-articulating hand that meets the basic user requirements. IEEE Transac Neural Syst Rehabil Eng. 2015;23(3):. doi:10.1109/TNSRE.2014.2342158

113. Khanicheh A, Muto A, Triantafyllou C, Weinberg B, Astrakas L, Tzika A, Mavroidis C. MR Compatible ERF Driven Hand Rehabilitation Device. In: 2005 IEEE 9th International Conference on Rehabilitation Robotics (ICORR). Chicago, IL; 2005. p. 7-12. doi:10.1109/ICORR.2005.1501039.

114. Khanicheh A, Muto A, Triantafyllou C, Weinberg B, Astrakas L, Tzika A, Mavroidis C. fMRI-compatible rehabilitation hand device. J NeuroEngineering Rehab. 2006;3(1):24. doi:10.1186/1743-0003-3-24.

115. Khanicheh A, Mintzopoulos D, Weinberg B, Tzika AA, Mavroidis C. MR_CHIROD v.2: magnetic resonance compatible smart hand rehabilitation device for brain imaging. IEEE Transac Neural Syst Rehabil Eng. 2008;16(1):91-8. doi:10.1109/TNSRE.2007.910286.

116. Wang F, Shastri M, Jones CL, Gupta V, Osswald C, Kang X, Kamper DG, Sarkar N. Design and control of an actuated thumb exoskeleton for hand rehabilitation following stroke. In: 2011 IEEE International Conference on Robotics and Automation (ICRA). Shanghai; 2011. p. 3688-693. doi:10.1109/ICRA.2011.5980099.

117. Fiorilla AE, Tsagarakis NG, Nori F, Sandini G. Design of a 2-finger hand exoskeleton for finger stiffness measurements. Appl Bion Biomechan. 2009;6(2):217-28. doi:10.1080/11762320902920567.

118. Ramos A, Halder S, Birbaumer N. Proprioceptive feedback in BCI. In: 2009 4th International IEEE/EMBS Conference on Neural Engineering. Antalya, Turkey; 2009. p. 279-82. doi:10.1109/NER.2009.5109287.

119. Ramos-Murguialday A, Schürholz M, Caggiano V, Wildgruber M, Caria A, Hammer EM, Halder S, Birbaumer N. Proprioceptive Feedback and Brain Computer Interface (BCI) Based Neuroprostheses. PLoS ONE. 2012;7(10):47048. doi:10.1371/journal.pone.0047048.

120. Tang Z, Sugano S, Iwata H. A novel, MRI compatible hand exoskeleton for finger rehabilitation. In: 2011 IEEE/SICE International Symposium on System Integration (SII). Kyoto; 2011. p. 118-23. doi:10.1109/SII.2011.6147430

121. Tang Z, Sugano S, Iwata H. Design of an MRI compatible robot for finger rehabilitation. In: 2012 IEEE International Conference on Mechatronics and Automation (ICMA). Chengdu; 2012. p. 611-6. doi:10.1109/ICMA.2012.6283177.

122. Tang Z, Sugano S, Iwata H. A finger exoskeleton for rehabilitation and brain image study. In: 2013 IEEE International Conference on Rehabilitation Robotics (ICORR). Seattle, WA; 2013. p. 1-6. doi:10.1109/ICORR.2013.6650446.

123. Tang Z, Sugano S, Iwata H. Design and evaluation of an one DOF finger rehabilitation device. In: 2013 IEEE/ASME International Conference on Advanced Intelligent Mechatronics (AIM). Wollongong; 2013. p. 822-7. doi:10.1109/AIM.2013.6584195.

124. Worsnopp TT, Peshkin MA, Colgate JE, Kamper DG. An actuated finger exoskeleton for hand rehabilitation following stroke. In: 2007 IEEE 10th Int Conf Rehabil Robot (ICORR). Noordwijk; 2007. p. 896-901. doi:10.1109/ICORR.2007.4428530

125. Jones CL, Wang F, Osswald C, Xuan Kang, Sarkar N, Kamper DG. Control and kinematic performance analysis of an Actuated Finger Exoskeleton for hand rehabilitation following stroke. In: 2010 3rd IEEE RAS and EMBS International Conference on Biomedical Robotics and Biomechatronics (BioRob). Tokyo; 2010. p. 282-7. doi:10.1109/BIOROB.2010.5626057.

126. Kim SJ, Jung Kim. MR-compatible hand exoskeleton for monitoring brain activity during active assistance. In: 2015 37th Annual International Conference of the IEEE Engineering in Medicine and Biology Society (EMBC). Milan; 2015. p. 5752-755. doi:10.1109/EMBC.2015.7319699. 
127. Lee J, Bae J. Design of a hand exoskeleton for biomechanical analysis of the stroke hand. In: 2015 IEEE International Conference on Rehabilitation Robotics (ICORR). Singapore; 2015. p. 484-9. doi:10.1109/ICORR.2015.7281246.

128. Interactive Motion Technologies: InMotion Robot-assisted Therapy: Evidence-Based Neurorehabilitation. 2013. http://interactive-motion com/wp-content/uploads/2013/10/EvidenceBasedNeurorehabilitation. pdf. Accessed 19 Oct 2015.

129. Interactive Motion Technologies: InMotion HAND ${ }^{\text {TM }}$. http://interactivemotion.com/healthcarereform/upper-extremity-rehabilitiation/ inmotion-hand/. Accessed 19 Oct 2015.

130. Birch B, Haslam E, Heerah I, Dechev N, Park EJ. Design of a continuous passive and active motion device for hand rehabilitation. In: 30th Annual International Conference of the IEEE Engineering in Medicine and Biology Society (EMBC). Vancouver, BC; 2008. p. 4306-309. doi:10.1109/IEMBS.2008.4650162

131. Fu Y, Wang P, Wang S, Liu H, Zhang F. Design and development of a portable exoskeleton based CPM machine for rehabilitation of hand injuries. In: 2007 IEEE International Conference on Robotics and Biomimetics (ROBIO). Sanya; 2007. p. 1476-1481. doi:10.1109/ROBIO.2007.4522382.

132. Nathan DE, Johnson MJ. Design of a Grasp Assistive Glove for ADL-focused, Robotic Assisted Therapy after Stroke. In: 2007 IEEE 10th International Conference on Rehabilitation Robotics (ICORR). Noordwijk; 2007. p. 943-50. doi:10.1109/ICORR.2007.4428537.

133. Nathan DE, Johnson MJ, McGuire JR. Design and validation of low-cost assistive glove for hand assessment and therapy during activity of daily living-focused robotic stroke therapy. J Rehabil Res Dev. 2009;46(5): 587-602. doi:10.1682/JRRD.2008.04.0052.

134. Park HS, Ren Y, Zhang LQ. IntelliArm: An exoskeleton for diagnosis and treatment of patients with neurological impairments. In: 2008 2nd Biennial IEEE RAS-EMBS International Conference on Biomedical Robotics and Biomechatronics (BioRob). Scottsdale, AZ; 2008. p. 109-14. doi:10.1109/BIOROB.2008.4762876.

135. Ren Y, Park HS, Zhang LQ. Developing a whole-arm exoskeleton robot with hand opening and closing mechanism for upper limb stroke rehabilitation. In: 2009 IEEE International Conference on Rehabilitation Robotics (ICORR). Kyoto; 2009. p. 761-5. doi:10.1109/ICORR.2009.5209482

136. Sun Z, Bao G, Yang Q, Wang Z. Design of a Novel Force Feedback Dataglove Based on Pneumatic Artificial Muscles. In: 2006 Int Conf Mechatron Autom. Luoyang; 2006. p. 968-72. doi:10.1109/ICMA.2006.257756.

137. Wang J, Li J, Zhang Y, Wang S. Design of an exoskeleton for index finger rehabilitation. In: 31 st Annual International Conference of the IEEE Engineering in Medicine and Biology Society (EMBC). Minneapolis, MN; 2009. p. 5957-960. doi:10.1109/IEMBS.2009.5334779.

138. Wang S, Li J, Zhang Y, Wang J. Active and Passive Control of an Exoskeleton with Cable Transmission for Hand Rehabilitation. In: 2009 2nd International Conference on Biomedical Engineering and Informatics. Tianjin; 2009. p. 1-5. doi:10.1109/BMEl.2009.5305113.

139. Wang S, Li J, Zheng R. Active and passive control algorithm for an exoskeleton with bowden cable transmission for hand rehabilitation. In: 2010 IEEE International Conference on Robotics and Biomimetics. Tianjin; 2010. p. 75-9. doi:10.1109/ROBIO.2010.5723306.

140. Wang S, Li J, Zheng R. A Resistance Compensation Control Algorithm for a Cable-Driven Hand Exoskeleton for Motor Function Rehabilitation. In: Intelligent Robotics and Applications; 2010. p. 398-404. doi:10.1007/978-3-642-16587-0_37.

141. Wang S, Li J, Zheng R, Chen Z, Zhang Y. Multiple rehabilitation motion control for hand with an exoskeleton. In: 2011 IEEE International Conference on Robotics and Automation (ICRA). Shanghai; 2011. p. 3676-681. doi:10.1109/ICRA.2011.5979696.

142. Yamaura H, Matsushita K, Kato R, Yokoi H. Development of hand rehabilitation system for paralysis patient - universal design using wire-driven mechanism. In: 31st Annual International Conference of the IEEE Engineering in Medicine and Biology Society (EMBC). Minneapolis, MN; 2009. p. 7122-125. doi:10.1109/IEMBS.2009.5332885.

143. Mihelj M, Podobnik J, Munih M. HEnRiE - Haptic environment for reaching and grasping exercise. In: 2008 2nd IEEE RAS \& EMBS International Conference on Biomedical Robotics and Biomechatronics. Scottsdale, AZ; 2008. p. 907-12. doi:10.1109/BIOROB.2008.4762810.
144. Podobnik J, Mihelj M, Munih M. Upper limb and grasp rehabilitation and evaluation of stroke patients using HenRiE device. In: 2009 Virtual Rehabilitation International Conference. Haifa; 2009. p. 173-8. doi:10.1109/ICVR.2009.5174227.

145. Podobnik J, Munih M. Robotic system for training of grasping and reaching. In: XII Mediterranean Conference on Medical and Biological Engineering and Computing 2010. Chalkidiki; 2010. p. 703-706. doi:10.1007/978-3-642-13039-7_177.

146. Kline T, Kamper DG, Schmit B. Control system for pneumatically controlled glove to assist in grasp activities. In: 2005 IEEE 9th International Conference on Rehabilitation Robotics (ICORR). Chicago, IL; 2005. p. 78-81. doi:10.1109/ICORR.2005.1501056.

147. Connelly L, Stoykov ME, Jia Y, Toro ML, Kenyon RV, Kamper DG. Use of a pneumatic glove for hand rehabilitation following stroke. In: $31 \mathrm{st}$ Annual International Conference of the IEEE Engineering in Medicine and Biology Society (EMBC). Minneapolis, MN; 2009. p. 2434-437. doi:10.1109/IEMBS.2009.5335400.

148. Connelly L, Jia Y, Toro ML, Stoykov ME, Kenyon RV, Kamper DG. A pneumatic glove and immersive virtual reality environment for hand rehabilitative training after stroke. IEEE Transac Neural Syst Rehabil Eng. 2010;18(5):551-9. doi:10.1109/TNSRE.2010.2047588.

149. Unluhisarcikli O, Weinberg B, Sivak M, Mirelman A, Bonato P, Mavroidis C. A robotic hand rehabilitation system with interactive gaming using novel Electro-Rheological Fluid based actuators. In: 2010 IEEE International Conference on Robotics and Automation (ICRA). Anchorage, AK; 2010. p. 1846-1851. doi:10.1109/ROBOT.2010.5509806.

150. Li J, Wang S, Wang J, Zheng R, Zhang Y, Chen Z. Development of a hand exoskeleton system for index finger rehabilitation. Chinese J Mech Eng. 2012;25(2):223-33. doi:10.3901/CJME.2012.02.223.

151. Kim HM, Kim GS. Development of a finger-rehabilitation robot for fingers' flexibility rehabilitation exercise. Int J Precis Eng Manuf. 2013;14(4):535-41. doi:10.1007/s12541-013-0073-3.

152. Sooraj R, Akshay N, Jeevan TG, Bhavani RR. Design and Analysis of a Parallel Haptic Orthosis for Upper Limb Rehabilitation. Int J Eng Tech. 5(1):444-51.

153. Tyromotion GmbH. http://tyromotion.com/. Accessed 23 Oct 2015.

154. Mayr A, Kollreider A, Ram D, Saltuari L. An electromechanical device for distal upper limb training: preliminary results. 2010. http://tyromotion. com/en/services/publications. Accessed 15 June 2016.

155. Hartwig M. Modern Hand- and Arm Rehabilitation: The Tyrosolution concept. Neurol Rehabil. 2014;2:111-6.

156. Cordo P, Lutsep H, Cordo L, Wright WG, Cacciatore T, Skoss R. Assisted movement with enhanced sensation (AMES): coupling motor and sensory to remediate motor deficits in chronic stroke patients. Neurorehabil Neural Repair. 2009;23(1):67-77. doi:10.1177/1545968308317437.

157. AMES Technology, Inc. http://www.amesdevices.com/. Accessed 23 Oct 2015

158. Ertas $\mid H$, Hocaoglu E, Barkana DE, Patoglu V. Finger exoskeleton for treatment of tendon injuries. In: 2009 IEEE International Conference on Rehabilitation Robotics (ICORR). Kyoto; 2009. p. 194-201. doi:10.1109/ICORR.2009.5209487.

159. Bi Q, Yang CJ. Design of a Hand Exoskeleton Rehabilitation Device. Adv Mater Res. 2011;328-330:1778-1783. doi:10.4028/www.scientific.net/AMR.328-330.1778.

160. Bi Q, Yang CJ, Deng XL, Fan JC. Contacting Mechanical Impedance of Human Finger based on Uncertain System. In: 2013 IEEE/ASME International Conference on Advanced Intelligent Mechatronics (AIM) Wollongong; 2013. p. 1619-1624.

161. Bi Q, Yang CJ. Human-machine interaction force control: using a model-referenced adaptive impedance device to control an index finger exoskeleton. J Zhejiang University SCIENCE C. 2014;15(4):275-83. doi:10.1631/jzus.C1300259.

162. Chan CL, Gobee S, Vickneswari D. Finger Grip Rehabilitation Using Exoskeleton with Grip Force Feedback In: Goh J, editor. 15th International Conference on Biomedical Engineering (IFBME). IFMBE Proceedings, vol. 43. Cham; 2014. p. 520-3. doi:10.1007/978-3-319-02913-9.

163. Taheri H, Rowe JB, Gardner D, Chan V, Reinkensmeyer DJ, Wolbrecht ET. Robot-assisted Guitar Hero for finger rehabilitation after stroke. In: 2012 Annual International Conference of the IEEE Engineering in 
Medicine and Biology Society. San Diego, CA; 2012. p. 3911-917. doi:10.1109/EMBC.2012.6346822.

164. Taheri H, Rowe JB, Gardner D, Chan V, Gray K, Bower C, Reinkensmeyer DJ, Wolbrecht ET. J NeuroEngineering Rehabil. 2014;1 1(1):10. doi:10.1186/1743-0003-11-10.

165. Zheng R, Li J. Kinematics and workspace analysis of an exoskeleton for thumb and index finger rehabilitation. In: 2010 IEEE International Conference on Robotics and Biomimetics. Tianjin; 2010. p. 80-4. doi:10.1109/ROBIO.2010.5723307.

166. Fu Y, Zhang Q, Zhang F, Gan Z. Design and development of a hand rehabilitation robot for patient-cooperative therapy following stroke. In: 2011 International Conference on Mechatronics and Automation (ICMA). Beijing; 2011. p. 112-7. doi:10.1109/ICMA.2011.5985641.

167. Zhang F, Fu Y, Wang T, Zhang Q, Wang S, Guo B. Research on sensing and measuring system for a hand rehabilitation robot. In: 2013 IEEE International Conference on Robotics and Biomimetics (ROBIO). Shenzhen; 2013. p. 50-5. doi:10.1109/ROBIO.2013.6739434.

168. Zhang F, Hua L, Fu Y, Chen H, Wang S. Design and development of a hand exoskeleton for rehabilitation of hand injuries. Mech Mach Theory. 2014;73:103-16. doi:10.1016/j.mechmachtheory.2013.10.015.

169. Kawasaki $H$, Ito $S$, Nishimoto $Y$, Kimura $H$, Hayashi H. Hand rehabilitation support system based on self-motion-control. In: First IEEE Technical Exhibition Based Conference on Robotics and Automation. Tokyo; 2004. p. 55-6. doi:10.1109/TEXCRA.2004.1424994.

170. Kawasaki H, Ito S, Ishigure Y, Nishimoto Y, Aoki T, Mouri T, Sakaeda H, Abe M. Development of a Hand Motion Assist Robot for Rehabilitation Therapy by Patient Self-Motion Control. In: 2007 IEEE 10th International Conference on Rehabilitation Robotics (ICORR),. Noordwijk; 2007. p. 234-40. doi:10.1109/ICORR.2007.4428432.

171. Ito $S$, Kawasaki H, Ishigure $Y$, Natsume M, Mouri T, Nishimoto Y. A design of fine motion assist equipment for disabled hand in robotic rehabilitation system. J Frankl Inst. 2011;348(1):79-89. doi:10.1016/j.jfranklin.2009.02.009.

172. Kawasaki H, Ito S, Nishimoto $Y$, Ueki S, Ishigure $Y$, Mouri T. Hand motion assist robot for rehabilitation therapy. J Robot Mechatron. 26(1):103-4.

173. Moromugi S, Kawakami K, Nakamura K, Sakamoto T, Ishimatsu T. A tendon-driven glove to restore finger function for disabled. In: ICROS-SICE International Joint Conference. Fukuoka; 2009. p. 794-7.

174. King CE, Wang PT, Mizuta M, Reinkensmeyer DJ, Do AH, Moromugi S, Nenadic Z. Noninvasive brain-computer interface driven hand orthosis. In: 2011 Annual International Conference of the IEEE Engineering in Medicine and Biology Society (EMBC). Boston, MA; 2011. p. 5786-789. doi:10.1109/IEMBS.2011.6091432.

175. McConnell A, Kong X, Vargas PA. A novel robotic assistive device for stroke-rehabilitation. In: The 23rd IEEE International Symposium on Robot and Human Interactive Communication. Edinburgh; 2014. p. 917-23. doi:10.1109/ROMAN.2014.6926370.

176. Yeong CF, Baker K, Melendez-Calderon A, Burdet E, Playford ED. ReachMAN to help sub-acute patients training reaching and manipulation. In: 2010 IEEE Conference on Robotics, Automation and Mechatronics (RAM). Singapore; 2010. p. 90-5. doi:10.1109/RAMECH.2010.5513206.

177. Zhu TL, Klein J, Dual SA, Leong TC, Burdet E. reachMAN2: A compact rehabilitation robot to train reaching and manipulation. In: 2014 IEEE/RSJ International Conference on Intelligent Robots and Systems (IROS). Chicago, IL; 2014. p. 2107-113. doi:10.1109/IROS.2014.6942845.

178. Hesse S, Kuhlmann H, Wilk J, Tomelleri C, Kirker SGB. A new electromechanical trainer for sensorimotor rehabilitation of paralysed fingers: a case series in chronic and acute stroke patients. J NeuroEngineering Rehabil. 2008;5(21):: doi:10.1186/1743-0003-5-21.

179. Reha-Stim Medtec GmbH \& Co. KG. Reha-Digit Flyer. 2012. http://www. reha-stim.de/cms/assets/files/Flyer/Reha-Digit\%20Flyer\%20Englisch \%202012.pdf. Accessed 16 Oct 2015.

180. Reha-Stim Medtec GmbH \& Co. KG. http://www.reha-stim.de/. Accessed 16 Oct 2015.

181. Ushiba J, Morishita A, Maeda T. A task-oriented brain-computer interface rehabilitation system for patients with stroke hemiplegia. In: 2014 4th International Conference on Wireless Communications, Vehicular Technology, Information Theory and Aerospace \& Electronic Systems (VITAE). Aalborg; 2014. p. 1-3. doi:10.1109/VITAE.2014.6934416.
182. Popescu N, Popescu D, Ivanescu M, Popescu D, Vladu C, Berceanu C, Poboroniuc M. Exoskeleton Design of an Intelligent Haptic Robotic Glove. In: 2013 19th International Conference on Control Systems and Computer Science. Bucharest; 2013. p. 196-202. doi:10.1109/CSCS.2013.21.

183. Popescu N, Popescu D, Poboroniuc M, Popescu CD. Intelligent Haptic Robotic Glove for patients diagnosed with cerebrovascular accidents. In: 2013 17th International Conference on System Theory, Control and Computing (ICSTCC). Sinaia; 2013. p. 717-21. doi:10.1109/ICSTCC.2013.6689045.

184. Hartopanu S, Poboroniuc M, Serea F, Irimia D, Livint G. Design of a hybrid FES-mechanical intelligent haptic robotic glove. In: 2013 17th International Conference on System Theory, Control and Computing (ICSTCC). Sinaia; 2013. p. 687-92. doi:10.1109/ICSTCC.2013.6689040.

185. Popescu D, Ivanescu M, Manoiu-Olaru S, Burtea M-i, Popescu N. Robotic glove development with application in robotics rehabilitation. In: 2014 International Conference and Exposition on Electrical and Power Engineering (EPE). lasi; 2014. p. 168-73. doi:10.1109/ICEPE.2014.6969890.

186. Hartopanu S, Poboroniuc M, Serea F, Livint G. Towards human arm rehabilitation in stroke patients by means of a hybrid FES \& robotic glove. In: 2014 International Conference and Exposition on Electrical and Power Engineering (EPE). lasi; 2014. p. 148-52. doi:10.1109/ICEPE.2014.6969886.

187. Popescu D, Ivanescu M, Manoiu-Olaru S, Popescu LC, Popescu N. Development of Robotic Gloves for Hand Rehabilitation Post-Stroke. In: 2015 20th International Conference on Control Systems and Computer Science. Bucharest; 2015. p. 838-44. doi:10.1109/CSCS.2015.95.

188. Gupta A, O'Malley MK, Patoglu V, Burgar C. Design, Control and Performance of RiceWrist: A Force Feedback Wrist Exoskeleton for Rehabilitation and Training. Int J Robot Res. 2008;27(2):233-51. doi:10.1177/0278364907084261.

189. Agarwal P, Deshpande AD. Impedance and force-field control of the index finger module of a hand exoskeleton for rehabilitation. In: 2015 IEEE International Conference on Rehabilitation Robotics (ICORR). Singapore; 2015. p. 85-90. doi:10.1109/ICORR.2015.7281180.

190. Agarwal P, Fox J, Yun Y, O'Malley MK, Deshpande AD. An index finger exoskeleton with series elastic actuation for rehabilitation: Design, control and performance characterization. Int J Robot Res. 2015;34(14): 1747-1772. doi:10.1177/0278364915598388.

191. Pehlivan AU, Sergi F, O'Malley MK. A Subject-Adaptive Controller for Wrist Robotic Rehabilitation. IEEE/ASME Transac Mechatron. 2015;20(3): 1338-1350. doi:10.1109/TMECH.2014.2340697.

192. Rose CG, Sergi F, Yun Y, Madden K, Deshpande AD, O'Malley MK. Characterization of a hand-wrist exoskeleton, READAPT, via kinematic analysis of redundant pointing tasks. In: 2015 IEEE International Conference on Rehabilitation Robotics (ICORR). Singapore; 2015. p. 205-10. doi:10.1109/ICORR.2015.7281200.

193. Luo X, Kline T, Fischer HC, Stubblefield K, Kenyon RV, Kamper DG. Integration of Augmented Reality and Assistive Devices for Post-Stroke Hand Opening Rehabilitation. In: 2005 IEEE Engineering in Medicine and Biology 27th Annual Conference. Shanghai; 2005. p. 6855-858. doi:10.1109/IEMBS.2005.1616080

194. Luo X, Kenyon RV, Kline T, Waldinger HC, Kamper DG. An Augmented Reality Training Environment for Post-Stroke Finger Extension Rehabilitation. In: 2005 IEEE 9th International Conference on Rehabilitation Robotics (ICORR). Chicago, IL; 2005. p. 329-32. doi:10.1109/ICORR.2005.1501112

195. Mulas M, Folgheraiter M, Gini G. An EMG-controlled exoskeleton for hand rehabilitation. In: 2005 IEEE 9th International Conference on Rehabilitation Robotics (ICORR), vol. 2005. Chicago, IL; 2005. p. 371-4. doi:10.1109/ICORR.2005.1501122.

196. Lambercy O, Dovat L, Johnson V, Salman B, Wong S, Gassert R, Milner T, Leong TC, Burdet E. Development of a Robot-Assisted Rehabilitation Therapy to train Hand Function for Activities of Daily Living. In: 2007 IEEE 10th International Conference on Rehabilitation Robotics (ICORR). Noordwijk; 2007. p. 678-82. doi:10.1109/ICORR.2007.4428498.

197. Winter SH, Bouzit M. Use of magnetorheological fluid in a force feedback glove. IEEE Transac Neural Syst Rehabil Eng. 2007;15(1):2-8 doi:10.1109/TNSRE.2007.891401.

198. Wege A, Kondak K, Hommel G. Mechanical design and motion control of a hand exoskeleton for rehabilitation. In: 2005 IEEE International 
Conference Mechatronics and Automation, vol. 1. Niagara Falls; 2005. p. 155-9. doi:10.1109/ICMA.2005.1626539.

199. Wege A, Hommel G. Embedded System Design for a Hand Exoskeleton. Dordrecht: Springer; 2006, pp. 169-76. doi:10.1007/1-4020-4933-1. ISBN: 978-1-4020-4932-3.

200. Wege A, Kondak K, Hommel G. Force Control Strategy for a Hand Exoskeleton Based on Sliding Mode Position Control. In: 2006 IEEE/RSJ International Conference on Intelligent Robots and Systems (IROS). Beijing; 2006. p. 4615-620. doi:10.1109/IROS.2006.282169.

201. Carpi F, Mannini A, De Rossi D. Elastomeric contractile actuators for hand rehabilitation splints In: Bar-Cohen Y, editor. Electroactive Polymer Actuators and Devices (EAPAD), vol. 6927; 2008. p. 692705. doi:10.1117/12.774644

202. Dovat L, Lambercy O, Gassert R, Maeder T, Milner T, Leong TC, Burdet E. HandCARE: A cable-actuated rehabilitation system to train hand function after stroke. IEEE Transac Neural Syst Rehabil Eng. 2008;16(6): 582-91. doi:10.1109/TNSRE.2008.2010347.

203. Chen M, Ho SK, Zhou HF, Pang PMK, Hu XL, Ng DTW, Tong KY. Interactive rehabilitation robot for hand function training. In: 2009 IEEE International Conference on Rehabilitation Robotics (ICORR). Kyoto; 2009. p. 777-80. doi:10.1109/ICORR.2009.5209564.

204. Hioki M, Kawasaki H, Sakaeda H, Nishimoto Y, Mouri T. Finger rehabilitation system using multi-fingered haptic interface robot controlled by surface electromyogram. In: 2010 3rd IEEE RAS and EMBS International Conference on Biomedical Robotics and Biomechatronics (BioRob). Tokyo; 2010. p. 276-81. doi:10.1109/BIOROB.2010.5626938.

205. Mohamaddan S, Komeda T. Wire-driven mechanism for finger rehabilitation device. In: 2010 IEEE International Conference on Mechatronics and Automation (ICMA). Xi'an; 2010. p. 1015-1018. doi:10.1109/ICMA.2010.5588077.

206. Oboe R, Daud Oa, Masiero S, Oscari F, Rosati G. Development of a haptic teleoperation system for remote motor and functional evaluation of hand in patients with neurological impairments. In: 2010 11th IEEE International Workshop on Advanced Motion Control (AMC). Nagaoka; 2010. p. 518-23. doi:10.1109/AMC.2010.5464078.

207. Burton TMW, Vaidyanathan R, Burgess SC, Turton AJ, Melhuish C. Development of a parametric kinematic model of the human hand and a novel robotic exoskeleton. In: 2011 IEEE International Conference on Rehabilitation Robotics (ICORR). Zurich; 2011. p. 1-7. doi:10.1109/ICORR.2011.5975344.

208. Burton TMW, Vaidyanathan R, Burgess SC, Turton AJ, Melhuish C. Sensitivity Analysis of a Parametric Hand Exoskeleton Designed to Match Natural Human Grasping Motion In: Herrmann G, Studley M, Pearson M, Conn A, Melhuish C, Witkowski M, Kim J-H, Vadakkepat P, editors. Lecture Notes in Computer Science vol. 7429. Bristol; 2012. p. 390-401. doi:10.1007/978-3-642-32527-4_35.

209. Ochoa JM, Jia Y, Dev N, Kamper DG. Development of a portable actuated orthotic glove to facilitate gross extension of the digits for therapeutic training after stroke. In: 2009 31st Annual International Conference of the IEEE Engineering in Medicine and Biology Society (EMBC). Minneapolis, MN; 2009. p. 6918-921. doi:10.1109/IEMBS.2009.5333630.

210. Wee TB, Ling SY. Development of a puppetry robotic glove system for the rehabilitation of upper limb functions. 5th International Conference on Rehabilitation Engineering Assistive Technology. Singapore; 2011. Article no. 18.

211. Hoffman HB, Blakey GL. New design of dynamic orthoses for neurological conditions. NeuroRehabilitation. 2011;28(1):55-61. doi:10.3233/NRE-2011-0632.

212. Saebo Inc. http://www.saebo.com/. Accessed 20 Oct 2015.

213. Tzemanaki A, Raabe D, Dogramadzi S. Development of a novel robotic system for hand rehabilitation. In: 2011 24th International Symposium on Computer-Based Medical Systems (CBMS). Bristol; 2011. p. 1-6. doi:10.1109/CBMS.2011.5999150.

214. Kim Y-m, Jung S-y, Moon I. Design of a wearable upper-limb rehabilitation robot using parallel mechanism. In: ICROS-SICE International Joint Conference. Fukuoka; 2009. p. 785-9.

215. Holmes CD, Wronkiewicz M, Somers T, Liu J, Russell E, Kim D, Rhoades C, Dunkley J, Bundy D, Galboa E, Leuthardt E. IPSIHAND BRAVO: An improved EEG-based brain-computer interface for hand motor control rehabilitation. In: 2012 Annual International Conference of the IEEE
Engineering in Medicine and Biology Society. San Diego, CA; 2012. p. 1749-1752. doi:10.1109/EMBC.2012.6346287.

216. Chiri A, Giovacchini F, Vitiello N, Cattin E, Roccella S, Vecchi F, Carrozza MC. HANDEXOS: Towards an exoskeleton device for the rehabilitation of the hand. In: 2009 IEEE/RSJ International Conference on Intelligent Robots and Systems (IROS). St. Louis, MO; 2009. p. 1106-1111. doi:10.1109/IROS.2009.5354376.

217. Chiri A, Cempini M, De Rossi SMM, Lenzi T, Giovacchini F, Vitiello N, Carrozza MC. On the design of ergonomic wearable robotic devices for motion assistance and rehabilitation. In: 2012 Annual International Conference of the IEEE Engineering in Medicine and Biology Society. San Diego, CA; 2012. p. 6124-127. doi:10.1109/EMBC.2012.6347391.

218. JACE Systems. http://www.jacesystems.com/. Accessed 20 Oct 2015.

219. Kazemi H, Kearney RE, Milner TE. A robotic interface to train grip strength, grip coordination and finger extension following stroke. In: 2012 Annual International Conference of the IEEE Engineering in Medicine and Biology Society, vol. 2012. San Diego, CA; 2012. p. 3903-906. doi:10.1109/EMBC.2012.6346820.

220. Naidu D, Stopforth R, Bright G, Davrajh S. A 7 DOF exoskeleton arm: Shoulder, elbow, wrist and hand mechanism for assistance to upper limb disabled individuals. In: IEEE Africon '11. Livingstone; 2011. p. 1-6. doi:10.1109/AFRCON.2011.6072065.

221. Naidu D, Stopforth R, Bright G, Davrajh S. A Portable Passive Physiotherapeutic Exoskeleton. International Journal of Advanced Robotic Systems. 2012;9:1. doi:10.5772/52065.

222. Polotto A, Modulo F, Flumian F, Xiao ZG, Boscariol P, Menon C. Index finger rehabilitation/assistive device. In: 2012 4th IEEE RAS \& EMBS International Conference on Biomedical Robotics and Biomechatronics (BioRob). Rome; 2012. p. 1518-1523. doi:10.1109/BioRob.2012.6290676.

223. QAL Medical, LLC. http://qalmedical.com/. Accessed 6 Nov 2015.

224. QAL Medical LLC. WaveFlex Specifications Sheet. 2012. http:// qalmedical.com/qalmed/wp-content/uploads/sites/28/2013/11/QALMedical-6000X-WaveFlex-HandCPM-CPM.pdf. Accessed 6 Nov 2015.

225. Torgerson C. Continuous passive motion device for the hand and a method of using the same. United States Patent Office. 1997. Patent no. US 5,697,892.

226. Wu J, Huang J, Wang Y, Xing $K$, Xu Q. Fuzzy PID control of a wearable rehabilitation robotic hand driven by pneumatic muscles. In: 2009 International Symposium on Micro-NanoMechatronics and Human Science. Nagoya; 2009. p. 408-13. doi:10.1109/MHS.2009.5352012.

227. Xing K, Huang J, Xu Q, Wang Y. Design of a wearable rehabilitation robotic hand actuated by pneumatic artificial muscles. In: 2009 7th Asian Control Conference. Hong Kong; 2009. p. 740-4.

228. TuX, Yu L, He J. Design of a Wearable Quantitative Muscle Rehabilitation Evaluation Robotic Hand Device In: Wang X, Wang F, Zhong S, editors. Lecture Notes in Electrical Engineering. Lecture Notes in Electrical Engineering, vol. 138. London; 2012. p. 1753-1761. doi:10.1007/978-1-4471-2467-2 208

229. Wu J, Huang J, Wang Y, Xing K. RLSESN-based PID adaptive control for a novel wearable rehabilitation robotic hand driven by PM-TS actuators. International Journal of Intelligent Computing and Cybernetics. 2012;5(1):91-110. doi:10.1108/17563781211208242.

230. Ab Rahim AH, Ab Patar MNAB, Amin ATM, Mahmud J. The Development of Finger Rehabilitation Device for Stroke Patients. Applied Mechanics and Materials. 2013;393:604-10. doi:10.4028/www.scientific.net/AMM.393.604.

231. Idrogenet, srl: Gloreha Lite. http://gloreha.com/. Accessed 23 Oct 2015.

232. Idrogenet, srl: Gloreha (Hand Rehabilitation Glove): summary of clinical results. 2013. http://www.gloreha.com/images/pdf/GLOREHA \%20Summary\%20of\%20Clinical\%20Results.pdf. Accessed 23 Oct 2015

233. Tong KY, Ho SK, Pang PMK, Hu XL, Tam WK, Fung KL, Wei XJ, Chen $\mathrm{PN}$, Chen M. An intention driven hand functions task training robotic system. In: 2010 Annual International Conference of the IEEE Engineering in Medicine and Biology Society (EMBC). Buenos Aires; 2010. p. 3406-409. doi:10.1109/IEMBS.2010.5627930.

234. Tong KY, Pang PMK, Chen M, Ho SK, Zhou H, Chan DTW. Wearable power assistive device for helping a user to move their hand: United States Patent Office; 2013. p. 27.

235. Ockenfeld C, Tong RKY, Susanto EA, Ho SK, Hu XL. Fine finger motor skill training with exoskeleton robotic hand in chronic stroke: Stroke rehabilitation. In: 2013 IEEE International Conference on Rehabilitation 
Robotics (ICORR). Seattle, WA; 2013. p. 1-4 doi:10.1109/ICORR.2013.6650392.

236. Rehab-Robotics Company Ltd. Hand of Hope. http://www.rehabrobotics.com/intro.html. Accessed 23 Oct 2015

237. Orlando MF, Akolkar H, Dutta A, Saxena A, Behera L. Optimal design and control of a hand exoskeleton. In: 2010 IEEE Conference on Robotics, Automation and Mechatronics (RAM). Singapore; 2010. p. 72-7. doi:10.1109/RAMECH.2010.5513211.

238. Ngeo J, Tamei T, Shibata T, Orlando MF, Behera L, Saxena A, Dutta A. Control of an optimal finger exoskeleton based on continuous joint angle estimation from EMG signals. In: 35th Annual International Conference of the IEEE Engineering in Medicine and Biology Society (EMBC). Osaka; 2013. p. 338-41. doi:10.1109/EMBC.2013.6609506.

239. Rahman A, Al-Jumaily A. Design and Development of a Hand Exoskeleton for Rehabilitation Following Stroke. Procedia Engineering. 2012;41:1028-1034. doi:10.1016/j.proeng.2012.07.279.

240. Rahman A, Al-Jumaily A. Design and development of a bilateral therapeutic hand device for stroke rehabilitation. International Journal of Advanced Robotic Systems. 2013;10:405. doi:10.5772/56809.

241. Shafi UA, Pervez A, Kamal FA, Ejaz R, Khan US, Iqbal J. Design and fabrication of an actuated hand exoskeleton for stroke and post traumatic rehabilitation. In: International Conference on Innovations in Engineering and Technology (ICIET). Bangkok; 2013. p. 176-80. doi:10.15242/IIE.E1213515.

242. Song K-t, Chai Y-y. Compliance control of wearable robotic fingers for rehabilitation applications. In: 2013 CACS International Automatic Control Conference (CACS). Sun Moon Lake; 2013. p. 306-11. doi:10.1109/CACS.2013.6734151.

243. Park JH, Lee K-s, Jeon K-h, Kim D-h, Park H-s. Low cost and light-weight multi-DOF exoskeleton for comprehensive upper limb rehabilitation. In: 201411 th International Conference on Ubiquitous Robots and Ambient Intelligence (URAI). Kuala Lumpur; 2014. p. 138-9. doi:10.1109/URAI.2014.7057415.

244. Kim D-h, Lee SW, Park HS. Feedback control of biomimetic exotendon device for hand rehabilitation in stroke. In: 36th Annual International Conference of the IEEE Engineering in Medicine and Biology Society (EMBC); 2014. p. 3618-621. doi:10.1109/EMBC.2014.6944406.

245. Coffey AL, Leamy DJ, Ward TE. A novel BCl-controlled pneumatic glove system for home-based neurorehabilitation. In: 36th Annual International Conference of the IEEE Engineering in Medicine and Biology Society. Chicago, IL; 2014. p. 3622-625. doi:10.1109/EMBC.2014.6944407.

246. Guo S, Zhang F, Wei W, Zhao F, Wang Y. Kinematic analysis of a nove exoskeleton finger rehabilitation robot for stroke patients. In: 2014 IEEE International Conference on Mechatronics and Automation (ICMA). Tianjin: 2014. p. 924-9. doi:10.1109/ICMA.2014.6885821.

247. Iqbal J, Tsagarakis NG, Fiorilla AE, Caldwell DG. A portable rehabilitation device for the hand. In: 2010 Annual International Conference of the IEEE Engineering in Medicine and Biology Society (EMBC). Buenos Aires; 2010. p. 3694-697. doi:10.1109/IEMBS.2010.5627448.

248. I labal J, Tsagarakis NG, Caldwell DG. Design of a wearable direct-driven optimized hand exoskeleton device. In: ACHI 2011 - 4th International Conference on Advances in Computer-Human Interactions. Gosier; 2011. p. 142-6.

249. Aubin P, Petersen K, Sallum H, Walsh CJ, Correia A, Stirling L. A pediatric robotic thumb exoskeleton for at-home rehabilitation: the isolated orthosis for thumb actuation (IOTA). International Journal of Intelligent Computing and Cybernetics. 2014;7(3):233-52. doi:10.1108/IJICC-10-2013-0043.

250. Kinetec SAS: Kinetec Maestra Portable CPM. http://www.kinetec.fr/en. Accessed 23 Oct 2015

251. Kinetec SAS: Kinetec CPMs. 2014. http://theratechequip.com/wpcontent/uploads/2014/04/Kinetec-knee-hand-elbow1.pdf. Accessed 23 Oct 2015.

252. Ab Patar MNAB, Komeda T, Mahmud J. Force assisted hand and finger device for rehabilitation. In: 2014 International Symposium on Technology Management and Emerging Technologies. Bandung; 2014. p. 133-8. doi:10.1109/ISTMET.2014.6936493.

253. Pu SW, Tsai SY, Chang JY. Design and development of the wearable hand exoskeleton system for rehabilitation of hand impaired patients. In: 2014 IEEE International Conference on Automation Science and
Engineering (CASE). Taipei; 2014. p. 996-1001. doi:10.1109/CoASE.2014.6899448.

254. Pu SW, Chang HT, Chang JY. Modeling and development of tension force measurement system for cable-driven hand exoskeleton robot. In: 2015 IEEE International Conference on Advanced Intelligent Mechatronics (AIM). Busan; 2015. p. 635-40. doi:10.1109/AIM.2015.7222608.

255. Meng QY, Tan SL, Yu HL, Meng QL, Yi JH. Research on Size Synthesis Optimization Design of a Bionic Exoskeleton for Index Finger Rehabilitation. Advanced Materials Research. 2014;945-949:1447-1450. doi:10.4028/www.scientific.net/AMR.945-949.1447.

256. Meng QY, Tan SL, Yu HL, Meng QL, Fang YF. Trajectory Planning and Realizing of an Exoskeleton Device for Hand Rehabilitation Based on sEMG Control. Applied Mechanics and Materials. 2014;536-537: 1015-1020. doi:10.4028/www.scientific.net/AMM.536-537.1015.

257. Metzger JC, Lambercy O, Chapuis D, Gassert R. Design and characterization of the ReHapticKnob, a robot for assessment and therapy of hand function. In: 2011 IEEE/RSJ International Conference on Intelligent Robots and Systems (IROS). San Francisco, CA; 2011. p. 3074-080. doi:10.1109/IROS.2011.6094882.

258. Metzger JC, Lambercy O, Gassert R. High-fidelity rendering of virtual objects with the ReHapticknob - novel avenues in robot-assisted rehabilitation of hand function. In: 2012 IEEE Haptics Symposium (HAPTICS). Vancouver, BC; 2012. p. 51-6. doi:10.1109/HAPTIC.2012.6183769.

259. Metzger JC, Lambercy O, Califfi A, Conti FM, Gassert R. Neurocognitive Robot-Assisted Therapy of Hand Function. IEEE Transactions on Haptics. 2014;7(2):140-9. doi:10.1109/TOH.2013.72.

260. Ates S, Lobo-Prat J, Lammertse P, van der Kooij H, Stienen AHA. SCRIPT passive orthosis: design and technical evaluation of the wrist and hand orthosis for rehabilitation training at home. In: 2013 IEEE International Conference on Rehabilitation Robotics (ICORR). Seattle, WA; 2013. p. 1-6. doi:10.1109/ICORR.2013.6650401.

261. Amirabdollahian F, Ates S, Basteris A, Cesario A, Buurke JH, Hermens HJ, Hofs D, Johansson E, Mountain G, Nasr N, Nijenhuis SM, Prange GB, Rahman N, Sale P, Schätzlein F, van Schooten B, Stienen AHA. Design, development and deployment of a hand/wrist exoskeleton for home-based rehabilitation after stroke - SCRIPT project. Robotica. 2014:32(08):1331-1346. doi:10.1017/S0263574714002288.

262. Chen Z, Fan S, Zhang D. An Exoskeleton System for Hand Rehabilitation Based on Master-Slave Control. In: Intelligent Robotics and Applications; 2014. p. 242-53. doi:10.1007/978-3-319-13966-1_25.

263. Wei W, Guo S, Zhang F, Guo J, Ji Y, Wang Y. A novel upper limb rehabilitation system with hand exoskeleton mechanism. In: 2013 IEEE International Conference on Mechatronics and Automation (ICMA). Takamatsu; 2013. p. 285-90. doi:10.1109//CMA.2013.6617932.

264. Wei W, Zhang W, Guo S, Zhao X, Wang Y. Development of an upper limb rehabilitation robot system for bilateral training. In: 2014 IEEE Int Conf Mechatron Autom (ICMA). Tianjin; 2014. p. 930-5. doi:10.1109/ICMA.2014.6885822.

265. Ab Patar MNAB, Komeda T, Low CY, Mahmud J. Model-based systems engineering of a hand rehabilitation device. Jurnal Teknologi. 2015;76(4): 185-90 doi:10.11113/jtv76.5496.

266. Ab Patar MNAB, Komeda T, Mahmud J, Low CY. Model Based Design of Finger Exoskeleton for Post Stroke Rehabilitation Using a Slotted Link Cam with Lead Screw Mechanism In: Gen M, Kim KJ, Huang X, Hiroshi $Y$, editors. Industrial Engineering, Management Science and Applications 2015. Lecture Notes in Electrical Engineering, vol. 349. Berlin, Heidelberg; 2015. p. 95-103. doi:10.1007/978-3-662-47200-2_11.

267. Iqbal J, Tsagarakis NG, Caldwell DG. A human hand compatible optimised exoskeleton system. In: 2010 IEEE International Conference on Robotics and Biomimetics. Tianjin; 2010. p. 685-90. doi:10.1109/ROBIO.2010.5723409

268. Iqbal J, Tsagarakis NG, Caldwell DG. A multi-DOF robotic exoskeleton interface for hand motion assistance. In: 2011 Annual International Conference of the IEEE Engineering in Medicine and Biology Society (EMBC). Boston, MA; 2011. p. 1575-1578. doi:10.1109/IEMBS.2011.6090458

269. Iqbal J, Ahmad O, Malik A. HEXOSYS II - towards realization of light mass robotics for the hand. In: 2011 IEEE 14th International Multitopic Conference. Karachi; 2011. p. 115-9. doi:10.1109/INMIC.2011.6151454. 
270. lqbal J, Caldwell DG, Tsagarakis NG. Four-fingered lightweight exoskeleton robotic device accommodating different hand sizes. Electron Letters. 2015;51(12):888-90. doi:10.1049/el.2015.0850.

271. Cempini M, De Rossi SMM, Lenzi T, Cortese M, Giovacchini F, Vitiello N, Carrozza MC. Kinematics and design of a portable and wearable exoskeleton for hand rehabilitation. In: 2013 IEEE International Conference on Rehabilitation Robotics (ICORR). Seattle, WA; 2013. doi:10.1109/ICORR.2013.6650414.

272. Cempini M, Vitiello N, Giovacchini F, De Rossi SMM, Lenzi T, Chiri A, Carrozza MC. Wearable exoskeleton device for hand rehabilitation. World Intellectual Property Organization. 2014. Patent no. WO 2014/033613 A2.

273. Cempini M, Cortese M, Vitiello N. A Powered Finger-Thumb Wearable Hand Exoskeleton With Self-Aligning Joint Axes. IEEE/ASME Transac Mechatron. 2015;20(2):705-16. doi:10.1109/TMECH.2014.2315528.

274. Cortese M, Cempini M, de Almeida Ribeiro PR, Soekadar SR, Carrozza MC, Vitiello N. A Mechatronic System for Robot-Mediated Hand Telerehabilitation. IEEE/ASME Transac Mechatron. 2015;20(4):1753-1764. doi:10.1109/TMECH.2014.2353298.

275. IJzerman MJ, Stoffers TS, in 't Groen F, Klatte MAP, Snoek GJ, Vorsteveld JHC, Nathan RH, Hermens HJ. J Rehab Sci. 9(3):86-9.

276. Bioness, Inc.: Ness H200 Brochure. 2013. http://www.bioness.com/ Documents/H200Consumer/H200_Wireless_Brochure_Update.pdf. Accessed 23 Oct 2015.

277. Ramirez J, Alfaro M, Chairez I. Electromyographic Driven Assisted Therapy for Hand Rehabilitation by Robotic Orthosis and Artificial Neural Networks In: Braidot A, Hadad A, editors. VI Latin American Congress on Biomedical Engineering CLAIB 2014. IFMBE Proceedings, vol. 49. Cham; 2015. p. 75-78. doi:10.1007/978-3-319-13117-7_20.

278. Richards DS, Georgilas I, Dagnino G, Dogramadzi S. Powered exoskeleton with palm degrees of freedom for hand rehabilitation. In: 2015 37th Annual International Conference of the IEEE Engineering in Medicine and Biology Society (EMBC). Milan; 2015. p. 4635-638. doi:10.1109/EMBC.2015.7319427.

279. Ates S, Moreno IM, Wessels M, Lammertse P, Stienen AHA. Three Stages of Development of the Robust SCRIPT Active Orthosis Session. In: Design of Medical Devices Conference Europe Edition. Delft; 2014. p. $56-7$.

280. Ates S, Mora-Moreno I, Wessels M, Stienen AHA. Combined active wrist and hand orthosis for home use: Lessons learned. In: 2015 IEEE International Conference on Rehabilitation Robotics (ICORR). Singapore; 2015. p. 398-403. doi:10.1109/ICORR.2015.7281232.

281. Mosher RS. From Handyman to Hardiman. SAE Technical Paper, 670088. 1967. doi:10.4271/670088.

282. Croshaw PF. Hardiman arm test. General Electric Company. 1969

283. Makinson JB. Research and Development Prototype for Machine Augmentation of Human Strength and Endurance. General Electric Company. 1971;196

284. Hamonet C, DeMontgolfier A. A new myoelectric prehension orthosis. Int Clinic Inf Bulletin. 1974;13(5):15-17.

285. Watanabe H, Ogata K, Okabe T, Amano T. Hand orthosis for various finger impairments-the K U finger splint. Prosthetics Orthot Int. 1978;2(2):95-100. doi:10.1080/03093647809177776.

286. Kang YS, Park YG, Lee BS, Park HS. Biomechanical evaluation of wrist-driven flexor hinge orthosis in persons with spinal cord injury. Rehabil Res Dev. 2013;50(8):1129-1138. doi:10.1682/JRRD.2012.10.0189.

287. North Coast Medical, Inc. https://www.ncmedical.com/. Accessed 23 Oct 2015.

288. Dollfus $\mathrm{P}$, Oberlé M. Technical note: preliminary communication a tridigital dynamic orthosis for tetraplegic patients. Paraplegia. 1984:22(2):115-8. doi:10.1038/sc.1984.20

289. Slack M, Berbrayer D. A myoelectrically controlled wrist-hand orthosis for brachial plexus injury: a case study. J Prosthetics Orthot. 4(3):171-4

290. Brown P, Jones D, Singh SK, Rosen JM. The exoskeleton glove for control of paralyzed hands. In: 1993 IEEE International Conference on Robotics and Automation (ICRA). Atlanta, GA; 1993. p. 642-7. doi:10.1109/ROBOT.1993.292051

291. DiCicco M, Lucas L, Matsuoka Y. Comparison of control strategies for an EMG controlled orthotic exoskeleton for the hand. In: 2004 IEEE International Conference on Robotics and Automation (ICRA), vol. 2; 2004. p. 1622-1627. doi:10.1109/ROBOT.2004.1308056.

292. Watanabe K, Morishita H, Mori T, Sato T. Grasping objects with the prototype of index-finger PIP joint motion amplifier for assisting rheumatoid arthritis patients. In: 2005 IEEE/ASME International Conference on Advanced Intelligent Mechatronics. Monterey, CA; 2005. p. 875-80. doi:10.1109/AIM.2005.1511119.

293. Alutei A, Vaida A, Mandru D, Tatar MO. Development of an Active Upper-Limb Orthosis. In: International Conference on Advancements of Medicine and Health Care Through Technology; 2009. p. 405-8. doi:10.1007/978-3-642-04292-8_89.

294. Moromugi S, Ishimatsu T, Matsui H, Ikeda T, Mizuta M, Koga T, Tateishi T, Saoyama T, Takashima M. An electrical prehension orthosis operated through activity of mastication muscle. In: SICE Annual Conference 2010. Taipei; 2010. p. 2030-033.

295. Broadened Horizons, Inc.: PowerGrip Assisted Grasp Orthosis. http:// www.broadenedhorizons.com/powergrip. Accessed 25 Oct 2015.

296. Toya K, Miyagawa T, Kubota Y. Power-Assist Glove Operated by Predicting the Grasping Mode. J Syst Design Dynam. 2011;5(1):94-108. doi:10.1299/jsdd.5.94.

297. Baqapuri HI, Nizami HA, Siddiqui S, Iqbal J, Shahbaz U. Prefabrication design of an actuated exoskeleton for traumatized and paralytic hands. In: 2012 International Conference of Robotics and Artificial Intelligence. Rawalpindi; 2012. p. 108-11. doi:10.1109/ICRAl.2012.6413404.

298. Hong MB, Kim SJ, Kim K. Development of a 10-DOF robotic system for upper-limb power assistance. In: 2012 9th International Conference on Ubiquitous Robots and Ambient Intelligence (URAI). Daejeon; 2012. p. 61-2. doi:10.1109/URAI.2012.6462931.

299. Hong MB, Kim SJ, Um T, Kim K. KULEX: An ADL power-assistance demonstration. In: 2013 10th International Conference on Ubiquitous Robots and Ambient Intelligence (URAI). Jeju; 2013. p. 542-4. doi:10.1109/URAI.2013.6677333.

300. Hong M, Kim SJ, Kim K. KULEX: ADL power assistant robotic system for the elderly and the disabled (Abstract for video). In: 2013 10th International Conference on Ubiquitous Robots and Ambient Intelligence (URAI). Jeju; 2013. p. 121-2. doi:10.1109/URAI.2013.6677487.

301. Lambercy O, Schröder D, Zwicker S, Gassert R. Design of a thumb exoskeleton for hand rehabilitation. In: Proceedings of the 7th International Convention on Rehabilitation Engineering and Assistive Technology. Singapore; 2013. p. 41.

302. Moromugi S, Tanaka T, Higashi T, Feng MQ, Ishimatsu T. Pneumatically Driven Prehension Orthosis with Force Control Function. J Robot Mechatron. 2013;25(6):973-82

303. Kudo S, Oshima K, Arizono M, Hayashi Y, Moromugi S. Electric-powered glove for $\mathrm{CCl}$ patients to extend their upper-extremity function. In: 2014 IEEE/SICE International Symposium on System Integration. Tokyo; 2014. p. 638-43. doi:10.1109/SII.2014.7028113.

304. Lee SJ, Kim YJ, Jeong GH, Yoon BR, Jho JY, Kim DM, Rhee K. Computational analyses of pinching dynamics of a finger exoskeleton composed of IPMC actuators. Int J Precis Eng Manuf. 2012;13(12): 2135-141. doi:10.1007/s12541-012-0283-0.

305. Nishad SS, Dutta A, Saxena A. Design and control of a three finger hand exoskeleton for translation of a slender object. In: 2014 11th International Conference on Ubiquitous Robots ands Ambient Intelligence (URAI). Kuala Lumpur; 2014. p. 179-84. doi:10.1109/URAI.2014.7057526.

306. Heo P, Kim SJ, Kim J. Powered finger exoskeleton having partially open fingerpad for flexion force assistance. In: 2013 IEEE/ASME International Conference on Advanced Intelligent Mechatronics (AIM), vol. 2. Wollongong; 2013. p. 182-7. doi:10.1109/AIM.2013.6584089.

307. Heo P, Kim J. Estimating grip forces with a tactilely transparent finger exoskeleton for pinch grip force assistance. In: 2014 IEEE Haptics Symposium. Houston, TX; 2014. p. 493-7. doi:10.1109/HAPTICS.2014.6775505.

308. Puzo ZC, Clark TA, Ulrey BL. Development of an assistive device controlled by surface electromyogram signals. In: 2014 40th Annual Northeast Bioengineering Conference (NEBEC). Boston, MA; 2014. p. 1-2. doi:10.1109/NEBEC.2014.6972912.

309. Sasaki D, Noritsugu T, Yamamoto H, Takaiwa M. Wearable power assist device for hand grasping using pneumatic artificial rubber muscle. In: 2004 SICE Annual Conference. Sapporo; 2004. p. 655-60. doi:10.1109/ROMAN.2004.1374840

310. Bergamasco M, Frisoli A, Fontana M, Loconsole C, Leonardis D, Troncossi M, Foumashi MM, Parenti-Castelli V. Preliminary results of BRAVO project: brain computer interfaces for Robotic enhanced Action in Visuo-motOr tasks. In: 2011 IEEE International Conference on 
Rehabilitation Robotics (ICORR). Zurich; 2011. p. 5975377. doi:10.1109/ICORR.2011.5975377.

311. Loconsole C, Leonardis D, Barsotti M, Solazzi M, Frisoli A, Bergamasco M, Troncossi M, Foumashi MM, Mazzotti C, Castelli VP. An emg-based robotic hand exoskeleton for bilateral training of grasp. In: 2013 World Haptics Conference (WHC). Daejeon; 2013. p. 537-42. doi:10.1109/WHC.2013.6548465.

312. Leonardis D, Barsotti M, Loconsole C, Solazzi M, Troncossi M, Mazzotti C, Castelli VP, Procopio C, Lamola G, Chisari C, Bergamasco M, Frisoli A. IEEE Transac Haptics. 2015;8(2):140-51. doi:10.1109/TOH.2015.2417570.

313. Conti R, Allotta B, Meli E, Ridolfi A. Development, design and validation of an assistive device for hand disabilities based on an innovative mechanism. Robotica FirstView. 2015.1-15. doi:10.1017/S0263574715000879.

314. Cui L, Phan A, Allison G. Design and fabrication of a three dimensional printable non-assembly articulated hand exoskeleton for rehabilitation. In: 2015 37th Annual International Conference of the IEEE Engineering in Medicine and Biology Society (EMBC). Milan; 2015. p. 4627-630. doi:10.1109/EMBC.2015.7319425.

315. Nycz CJ, Delph MA, Fischer GS. Modeling and design of a tendon actuated soft robotic exoskeleton for hemiparetic upper limb rehabilitation. In: 2015 37th Annual International Conference of the IEEE Engineering in Medicine and Biology Society (EMBC). Milan; 2015. p. 3889-892. doi:10.1109/EMBC.2015.7319243.

316. Low JH, Ang MH, Yeow CH. Customizable soft pneumatic finger actuators for hand orthotic and prosthetic applications. In: 2015 IEEE International Conference on Rehabilitation Robotics (ICORR). Singapore; 2015. p. 380-5. doi:10.1109/ICORR.2015.7281229.

317. Yap HK, Lim JH, Nasrallah F, Goh JCH, Yeow RCH. A soft exoskeleton for hand assistive and rehabilitation application using pneumatic actuators with variable stiffness. In: 2015 IEEE International Conference on Robotics and Automation (ICRA). Seattle, WA; 2015. p. 4967-972. doi:10.1109/ICRA.2015.7139889

318. Yap HK, Goh JCH, Yeow RCH. Design and Characterization of Soft Actuator for Hand Rehabilitation Application. In: IFMBE Proceedings; 2015. p. 367-70. doi:10.1007/978-3-319-11128-5 92.

319. Yap HK, Lim JH, Nasrallah F, Low FZ, Goh JCH, Yeow RCH. MRC-glove: A fMRI compatible soft robotic glove for hand rehabilitation application. In: 2015 IEEE International Conference on Rehabilitation Robotics (ICORR). Singapore; 2015. p. 735-40. doi:10.1109/ICORR.2015.7281289.

320. Gasser BW, Goldfarb M. Design and performance characterization of a hand orthosis prototype to aid activities of daily living in a post-stroke population. In: 2015 37th Annual International Conference of the IEEE Engineering in Medicine and Biology Society (EMBC). Milan; 2015. p. 3877-880. doi:10.1109/EMBC.2015.7319240

321. Hasegawa Y, Mikami Y, Watanabe K, Sankai Y. Five-fingered assistive hand with mechanical compliance of human finger. In: 2008 IEEE International Conference on Robotics and Automation (ICRA). Pasadena, CA; 2008. p. 718-24. doi:10.1109/ROBOT.2008.4543290.

322. Hasegawa $Y$, Watanabe $K$, Sankai Y. Performance evaluations of hand and forearm support system. In: 2010 IEEE/RSJ International Conference on Intelligent Robots and Systems (IROS). Taipei; 2010. p. 2645-650. doi:10.1109/IROS.2010.5650355.

323. Hasegawa Y, Tokita J, Kamibayashi K, Sankai Y. Evaluation of fingertip force accuracy in different support conditions of exoskeleton. In: 2011 IEEE International Conference on Robotics and Automation (ICRA). Shanghai; 2011. p. 680-5. doi:10.1109/ICRA.2011.5980512.

324. Hasegawa Y, Ariyama T, Kamibayashi K. Pinching force accuracy affected by thumb sensation in human force augmentation. In: 2012 IEEE/RSJ International Conference on Intelligent Robots and Systems (IROS). Vilamoura; 2012. p. 3943-948. doi:10.1109/IROS.2012.6386081.

325. Hasegawa $Y$, Muto J. Superiority of pinching force accuracy augmented by exoskeletal support system. In: 2013 IEEE/RSJ International Conference on Intelligent Robots and Systems (IROS). Tokyo; 2013. p. 3771-776. doi:10.1109/IROS.2013.6696895.

326. Hasegawa $Y$, Suzuki T. Thin and active fixture to hold finger for easy attachment and comfort of grasping support exoskeleton. In: 2015 IEEE International Conference on Robotics and Automation (ICRA). Seattle, WA; 2015. p. 4973-978. doi:10.1109/ICRA.2015.7139890.

327. Rotella MF, Reuther KE, Hofmann CL, Hage EB, BuSha BF. An orthotic hand-assistive exoskeleton for actuated pinch and grasp. In: 2009 IEEE 35th Annual Northeast Conference Bioengineering Conference. Boston, MA; 2009. p. 1-2. doi:10.1109/NEBC.2009.4967693.

328. Martinez LA, Olaloye OO, Talarico MV, Shah SM, Arends RJ, BuSha BF A power-assisted exoskeleton optimized for pinching and grasping motions. In: 2010 IEEE 36th Annual Northeast Bioengineering Conference (NEBEC). New York, NY; 2010. p. 1-2. doi:10.1109/NEBC.2010.5458232.

329. Colon M, Hamid Y, Lopez J, Scully L, Kim S, BuSha BF. 3-D printed hand assisstive exoskeleton for actuated pinch and grasp. In: 2014 40th Annual Northeast Bioengineering Conference (NEBEC). Boston, MA; 2014. p. 1-2. doi:10.1109/NEBEC.2014.6972761.

330. Cincotti CC, O'Donnell S, Zapata GE, Rabolli CM, BuSha BF. Strength amplifying hand exoskeleton. In: 2015 41st Annual Northeast Biomedical Engineering Conference (NEBEC). Troy, NY; 2015. p. 1-2. doi:10.1109/NEBEC.2015.7117082.

331. Polygerinos P, Lyne S, Wang Z, Nicolini LF, Mosadegh B, Whitesides GM, Walsh CJ. Towards a soft pneumatic glove for hand rehabilitation. In: 2013 IEEE/RSJ International Conference on Intelligent Robots and Systems (IROS). Tokyo; 2013. p. 1512-1517. doi:10.1109/IROS.2013.6696549.

332. Polygerinos P, Galloway KC, Savage E, Herman M, Donnell KO, Walsh CJ. Soft robotic glove for hand rehabilitation and task specific training. In: 2015 IEEE International Conference on Robotics and Automation (ICRA). Seattle, WA; 2015. p. 2913-919. doi:10.1109/ICRA.2015.7139597.

333. Jeong $\mathrm{U}$, In HK, Cho KJ. Implementation of various control algorithms for hand rehabilitation exercise using wearable robotic hand. Int Serv Robot. 2013;6(4):181-9. doi:10.1007/s11370-013-0135-5.

334. Jeong $\mathrm{U}$, In $\mathrm{H}$, Lee $\mathrm{H}$, Kang BB, Cho K-j. Investigation on the control strategy of soft wearable robotic hand with slack enabling tendon actuator. In: 2015 IEEE International Conference on Robotics and Automation (ICRA). Seattle, WA; 2015. p. 5004-009. doi:10.1109/ICRA.2015.7139895.

335. In H, Kang BB, Sin M, Cho K-j. Exo-Glove: A Wearable Robot for the Hand with a Soft Tendon Routing System. IEEE Rob Autom Mag. 2015;22(1):97-105. doi:10.1109/MRA.2014.2362863.

336. Yamada Y, Morizono T, Sato S, Shimohira T, Umetani Y, Yoshida T, Aoki S. Proposal of a SkilMate finger for EVA gloves. In: 2001 IEEE International Conference on Robotics and Automation (ICRA), vol. 2 Seoul; 2001. p. 1406-1412. doi:10.1109/ROBOT.2001.932807.

337. Choi BH, Choi HR. A semi-direct drive hand exoskeleton using ultrasonic motor. In: 8th IEEE International Workshop on Robot and Human Interaction (RO-MAN). Pisa; 1999. p. 285-90. doi:10.1109/ROMAN.1999.900354.

338. Koyama T, Yamano I, Takemura K, Maeno T. Multi-fingered exoskeleton haptic device using passive force feedback for dextrous telemanipulation. In: 2002 IEEE/RSJ International Conference on Intelligent Robots and Systems. Lausanne: 2002. p. 2905-910.

339. Tzafestas CS. Whole-hand kinesthetic feedback and haptic perception in dextrous virtual manipulation. IEEE Transac Syst Man Cybernet Part A: Syst Humans. 2003;33(1):100-13. doi:10.1109/TSMCA.2003.812600.

340. Lelieveld MJ, Maeno T. Design and development of a 4 DOF portable haptic interface with multi-point passive force feedback for the index finger. In: 2006 IEEE International Conference on Robotics and Automation (ICRA). Orlando, FL; 2006. p. 3134-139. doi:10.1109/ROBOT.2006.1642178.

341. Nakagawara S, Kajimoto H, Kawakami N, Tachi S, Kawabuchi I. An encounter-type multi-fingered master hand using circuitous joints. In: 2005 IEEE International Conference on Robotics and Automation (ICRA), vol. 2005. Barcelona; 2005. p. 2667-672. doi:10.1109/ROBOT.2005.1570516.

342. Sato K, Minamizawa K, Kawakami N, Tachi S. Haptic telexistence. In: ACM SIGGRAPH 2007: 2007. p. 10. doi:10.1145/1278280.1278291.

343. CyberGrasp Systems LLC. CyberGrasp Brochure. http://www.bienetec. es/sites/default/files/cybergrasp_brochure_2009.pdf. Accessed 30 Oct 20152009.

344. Fang $\mathrm{H}$, Xie Z, Liu H. An exoskeleton master hand for controlling DLR/HIT hand. In: 2009 IEEE/RSJ International Conference on Intelligent Robots and Systems (IROS). St. Louis, MO; 2009. p. 3703-708. doi:10.1109/IROS.2009.5354624.

345. Fang H, Xie Z, Liu H, Lan T, Xia J. An exoskeleton force feedback master finger distinguishing contact and non-contact mode. In: 2009 IEEE/ASME 
International Conference on Advanced Intelligent Mechatronics. Singapore; 2009. p. 1059-1064. doi:10.1109/AIM.2009.5229726.

346. Charoenseang S, Panjan S. 5-Finger Exoskeleton for Assembly Training in Augmented Reality. In: Virtual and Mixed Reality - New Trends vol, 6773. Orlando, FL; 2011. p. 30-39. doi:10.1007/978-3-642-22021-0_4.

347. Fontana M, Dettori A, Salsedo F, Bergamasco M. Mechanical design of a novel Hand Exoskeleton for accurate force displaying. In: 2009 IEEE International Conference on Robotics and Automation (ICRA). Kobe; 2009. p. 1704-1709. doi:10.1109/ROBOT.2009.5152591.

348. Fontana M, Salsedo F, Marcheschi S, Bergamasco M. Haptic hand exoskeleton for precision grasp simulation. J Mech Robot. 2013;5(4): 041014. doi:10.1115/1.4024981.

349. Dexta Robotics. Dexmo: an exoskeleton for you to touch the digital world. https://www.kickstarter.com/projects/1277630932/dexmo-anexoskeleton-for-you-to-touch-the-digital. Accessed 30 Oct 2015.

350. Dexta Robotics. http://www. dextarobotics.com/. Accessed 30 Oct 2015.

351. Liu L, Miyake S, Maruyama N, Akahane K, Sato M. Development of two-handed multi-finger haptic interface SPIDAR-10. In: Eurohaptics. Lecture Notes in Computer Science. Versailles; 2014. p. 176-183. doi:10.1007/978-3-662-44196-1_22.

352. Jo I, Bae J. Kinematic analysis of a hand exoskeleton structure. In: 2013 10th International Conference on Ubiquitous Robots and Ambient Intelligence (URAI). Jeju; 2013. p. 457-8. doi:10.1109/URAl.2013.6677310.

353. Jo I, Bae J. Design and control of a wearable hand exoskeleton with force-controllable and compact actuator modules. In: 2015 IEEE International Conference on Robotics and Automation (ICRA). Seattle, WA; 2015. p. 5596-601. doi:10.1109/ICRA.2015.7139982.

354. Ben-Tzvi P, Ma Z. Sensing and Force-Feedback Exoskeleton (SAFE) Robotic Glove. IEEE Transac Neural Syst Rehabil Eng. 2015;23(6): 992-1002. doi:10.1109/TNSRE.2014.2378171.

355. Ma Z, Ben-Tzvi P. RML Glove - An Exoskeleton Glove Mechanism With Haptics Feedback. IEEE/ASME Transac Mechatron. 2015;20(2):641-52. doi:10.1109/TMECH.2014.2305842.

\section{Submit your next manuscript to BioMed Central and we will help you at every step:}

- We accept pre-submission inquiries

- Our selector tool helps you to find the most relevant journal

- We provide round the clock customer support

- Convenient online submission

- Thorough peer review

- Inclusion in PubMed and all major indexing services

- Maximum visibility for your research

Submit your manuscript at www.biomedcentral.com/submit 